\title{
Composing criteria of individuation in copredication*
}

\author{
Matthew Gotham \\ Department of Linguistics, UCL \\ IFIKK, University of Oslo
}

\begin{abstract}
Copredication is the phenomenon whereby two or more predicates are applied to a single argument, but those predicates appear to require that their argument denote different things. This paper focuses on the problem of individuation and counting in copredication: many quantified copredication sentences have truth conditions that cannot be accounted for given standard assumptions, because the predicates used impose distinct criteria of individuation on the objects to which they apply. I propose a compositional system for criteria of individuation and show that it improves predictions regarding the truth conditions of numerically quantified copredication sentences compared to existing accounts.
\end{abstract}

\section{Introduction}

Copredication is the phenomenon whereby two (or more) predicates are applied to a single argument, but those predicates appear to require that their argument denote different things (Pustejovsky, 1995, 236). Some examples are given in (1)-(3).

(1) The heavy book is easy to understand.

(2) Lunch was delicious but took forever. (Asher, 2011, 11)

(3) London is so unhappy, ugly and polluted that it should be destroyed and rebuilt 100 miles away. (Chomsky, 2000, 37)

There are several different ways in which copredication poses challenges to linguistic theory. It raises philosophical questions about the place of a reference relation in semantics. What, if anything, should the referents of 'book', 'lunch' and 'London' be taken to be in sentences like (1)-(3) respectively? It also presents difficulties concerning the ascription of selectional requirements to predicates in framing a theory of semantic anomaly. How can apparently sortally conflicting predicates, such as 'delicious' and 'took forever', for example, be applied to a single syntactic argument?

${ }^{*}$ This is a pre-copyedited, author-produced PDF of an article accepted for publication in the Journal of Semantics following peer review. The version of record, DOI 10.1093/jos/ffw008, is available online at: http://jos. oxfordjournals.org/cgi/content/full/ffw008?ijkey=wEc4IUWgHPg5lpY\&keytype=ref. 
Important and interesting though these challenge are, they will not be my focus in this paper. Instead, I will concentrate on an issue that cuts across them both, namely how to account for the interpretations that quantified copredication sentences have. In many cases this cannot be done given standard assumptions, because the different predicates used in copredication sentences impose distinct criteria of individuation on the objects to which they apply.

Chomsky $(2000,16)$ asks us to imagine the following scenario:

Suppose the library has two copies of Tolstoy's War and Peace, Peter takes out one, and John the other. Did Peter and John take out the same book, or different books? If we attend to the material factor of the lexical item, they took out different books; if we focus on its abstract component, they took out the same book. We can attend to both material and abstract factors simultaneously...

When we 'attend to both material and abstract factors simultaneously', then we have copredication, as shown for example in (1) above and (6) below. In contrast, in (4) 'we attend to the material factor of the lexical item', and in (5) 'we focus on its abstract component'.

(4) Three books are heavy.

(5) Three books are informative.

(6) Three informative books are heavy.

In each of (4)-(6) we have 'three books'; however, what counts as three books differs. For example, (4) can be true if there are three copies of the same book, each of which is heavy. However, it would not be true if there were (only) three informational books in one heavy volume. In the former case, individuated physically there are three books, while individuated informationally there is one book; in the latter case, the opposite is true. Conversely, (5) can be true if each of the three books in a single heavy volume are informative, but it would not be true if there were (only) three heavy copies of the same informative book. In the former case, individuated informationally there are three books, while individuated physically there is one book; in the latter case, the opposite is true.

The counting principles involved in (4)-(5), of course, are unsurprising, and in some sense must follow from the fact that the predicate 'heavy' requires or expects its grammatical argument to denote something physical, while the predicate 'informative' requires or expects its grammatical argument to denote something informational. ${ }^{1}$ If it were not for copredication then it would make sense to say that 'book' is simply ambiguous and that in (4) a different sense of the word (or a different word) is used than in (5), i.e. that in (4) 'book' denotes a set of physical books, while in (5) it denotes a set of informational books. However, this approach cannot be maintained for (6), because in that sentence neither of the aforementioned senses is adequate to account for the truth conditions of the sentence: (6) is true neither if three copies of the same informative book are heavy (and no others), nor if there is (only) one heavy volume in which three informative books are printed. For (6) to be true there must be three books individuated both physically and informationally.

\footnotetext{
${ }^{1}$ Or perhaps, this is what hearers expect, given the use of these predicates.
} 
In this paper, I will describe a theory that correctly predicts the truth conditions of (4)(6) and sentences like them. My proposal is that a noun supporting copredication, such as 'book' or 'lunch', has composite objects in its extension. So, for example, the reason that a sentence like (1) can be acceptable and true is that there can be objects in the extension of 'book' that can be both heavy and easy to understand; and the reason that a sentence like (2) can be acceptable and true is that there can be objects in the extension of 'lunch' that can both be delicious and take forever. This mereological approach to nouns supporting copredication does empirical work in deriving the correct truth conditions for numerically quantified sentences like (4)-(6). Viewing the extension of these nouns as sets of composite objects allows us to compare those objects across different dimensions determined by their parts.

The paper is structured as follows. Section 2 gives a conceptual outline of the approach to copredication being proposed. In Section 3 I describe the formal system that predicts the truth conditions of copredication sentences. This is done in stages, with a simplified version of the system presented in Section 3.1 and the the final version presented in Sections 3.2 and 3.3. In Section 4 I compare this account of copredication to three other prominent accounts in the literature. Section 5 concludes.

\section{A revised mereological approach to copredication}

Saying that nouns like 'book' and 'lunch' have composite objects in their extensions still leaves many questions to be answered. What is the structure of those objects? And what are their properties? I will assume that a noun supporting copredication has in its extension a set of objects, each member of which is made up of two parts. For example, 'book' denotes the set of composite objects $p+i$, where $p$ is a physical book and $i$ is an informational book instantiated by $p$. I also assume that any property that holds of $p$ holds of $p+i$, and likewise any property that holds of $i$ also holds of $p+i$. So for example, if $v_{1}$ is a physical volume instantiating War and Peace (conceived of as a purely informational, or 'abstract', object), and $v_{1}$ is heavy, then $v_{1}+$ War and Peace is heavy. Likewise, $v_{1}+$ War and Peace is by Tolstoy, in virtue of War and Peace being by Tolstoy. ${ }^{2}$

The idea that nouns supporting copredication, such as 'book' and 'lunch', might denote sets of composite objects of this kind is not a new one. In an analysis of (2), Cooper (2007, 4) suggests that:

the lunch is delicious in virtue of the food which is part of the lunch being delicious. It is common in natural language for us to make predications of objects in terms of predications that hold of some of their parts, though not all of them.

However, there is an obvious problem with this kind of approach, as Asher $(2011,146-7)$ points out. Suppose we have a small Dostoyevsky library consisting of two volumes, each of

\footnotetext{
${ }^{2}$ One can imagine other ways of implementing this mereological approach to copredication, both in terms of what composite objects there are and in terms of what their properties are. That in turn would require a revision to the definition of compressibility in Section 3.1.1. The approach adopted in this paper is adequate for criteria of individuation to be determined compositionally, and can be adapted if revisions of this kind turn out to be necessary (Gotham, 2014, §3.6.2).
} 
volume 1

Notes from Underground
The Gambler

volume $2 \quad \begin{gathered}\text { Notes from Underground } \\ \text { The Gambler }\end{gathered}$

Figure 1: A small Dostoyevsky library

which contains both the novellas Notes from Underground and The Gambler (illustrated in Figure 1). On the assumptions made so far in this section, the set of books in that situation would be the set shown in (7), given that, according to a widely-accepted axiom of mereology, two objects are distinct if any of their parts are distinct (Varzi, 2012). ${ }^{3}$

$$
\left\{v_{1}+N f U, v_{2}+N f U, v_{1}+T G, v_{2}+T G\right\}
$$

Suppose that all the books in the library shown in Figure 1 (and no others) are heavy and informative. None of (4)-(6) would be true: it is not the case that three books are heavy (only two), it is not the case that three books are informative (only two), and $a$ fortiori it is not the case that three books are heavy and informative. However, if the simple mererological picture painted above were right, then all three sentences would be true, since (7) indicates that, conceived of as composite objects made up of physical and informational parts, there are four books in this situation that are heavy and are informative. ${ }^{4}$ Partly for this reason, Cooper (2011) has subsequently adopted a different approach to copredication, which I will discuss in Section 4.2.

However, this mereological approach to nouns supporting copredication can be improved in a revised mereological approach, so that truth conditions are derived for (4)-(6) as expressed in (8)-(10) respectively. In (8)-(10), 'book' is to be taken to mean a composite object made up of one part that is a physical book and one part that is an informational book instantiated by it.

(8) There is a plurality $s$ of three books such that:

Every member of $s$ is physically distinct from every other member.

Every member of $s$ is heavy.

(9) There is a plurality $s$ of three books such that:

Every member of $s$ is informationally distinct from every other member.

Every member of $s$ is informative.

(10) There is a plurality $s$ of three books such that:

Every member of $s$ is physically and informationally distinct from every other member.

\footnotetext{
${ }^{3}$ The '+' symbols here indicates the parts making up a single composite object, not individuals making up a plurality. So for example $a+b$ indicates a singular object, while $a \oplus b$ indicates a plurality. Cf. Figure 2 .

${ }^{4}$ Here and throughout this paper, a simple numeral ' $n$ ' is taken to mean 'at least $n$ ', and lexical entries are given accordingly.
} 
Each member of $s$ is informative.

Each member of $s$ is heavy.

As can be seen from (8)-(10), one aim of this approach is to avoid the pitfalls of a naïve mereological account, by introducing the requirement that the individual books being counted must all be distinct from each other in defined ways. The approach that will be taken in confronting this issue is to formalize and refine this notion of distinctness, and use it for the purposes of counting when computing the truth conditions of sentences like (4)-(6). The underlying idea is that, while (7) may well accurately represent the set of books in a given situation, this set is never used in determining truth conditions without being somehow modified.

The question then becomes, how are the right distinctness requirements, as outlined in (8)-(10), to be introduced compositionally in each case? Clearly, in order to derive (8)-(10) respectively as the truth conditions for (4)-(6) in a compositional manner, the notions of physical and informational distinctness must play a role in the theory. Exactly what these notions mean, and how they are used, will be explained in Section 3 below.

\section{Composing criteria of individuation}

\subsection{Basic concepts}

\subsubsection{Preliminaries}

I am assuming the ontology of plurals described by Link (1983), such that the domain of type $e$ contains both singular objects and proper pluralities. $a \oplus b$ indicates the plurality made up of $a$ and $b$. Additionally, I will use $a+b$ to indicate the single composite object made up of parts $a$ and $b$. So, for example, $a+b \oplus c+d$ indicates the two-membered plurality made up of the composite objects $a+b$ and $c+d$. I am assuming that the composite object-forming operator ' + ' requires arguments that are singular objects and not (proper) pluralities, so e.g. $a+(b \oplus c)$ is not well-formed.

(8)-(10) give the target truth conditions for our treatment of (4)-(6) respectively. In the metalanguage to be used, (10) translates as (11). ${ }^{5}$

$$
\begin{aligned}
& \exists x\left(|x| \geq 3 \wedge * \operatorname{inform}^{\prime}(x) \wedge * \operatorname{book}^{\prime}(x) \wedge * \operatorname{heavy}^{\prime}(x)\right. \\
& \wedge \neg \exists y \exists z\left(y \neq z \wedge \mathrm{i}-\operatorname{part}^{\prime}(y, x) \wedge \mathrm{i}-\operatorname{part}^{\prime}(z, x) \wedge \mathrm{i}-\operatorname{atom}^{\prime}(y) \wedge \mathrm{i}-\operatorname{atom}^{\prime}(z)\right. \\
& \left.\left.\wedge\left(\operatorname{phys-equiv}^{\prime}(y, z) \vee \text { info-equiv }^{\prime}(y, z)\right)\right)\right)
\end{aligned}
$$

In English: there is a plurality of three books, each of which is heavy and informative, and no two distinct singular objects in that plurality are physically or informationally equivalent to each other. Following Link (1983), ${ }^{*} P$ is the characteristic function of the set of (possibly singular) pluralities formed from entities in the extension of $P$ :

$$
\begin{aligned}
& \forall x\left(P(x) \rightarrow{ }^{*} P(x)\right) \\
& \forall x \forall y\left(\left({ }^{*} P(x) \wedge^{*} P(y)\right) \leftrightarrow{ }^{*} P(x \oplus y)\right)
\end{aligned}
$$

\footnotetext{
${ }^{5}$ To say that $|x| \geq n$ is just to say that there are at least $n$ atomic parts of $x$, i.e. $\mid\left\{y: \mathrm{i}-\operatorname{part}^{\prime}(y, x) \wedge\right.$ i-atom' $\left.(y)\right\} \mid \geq n$.
} 


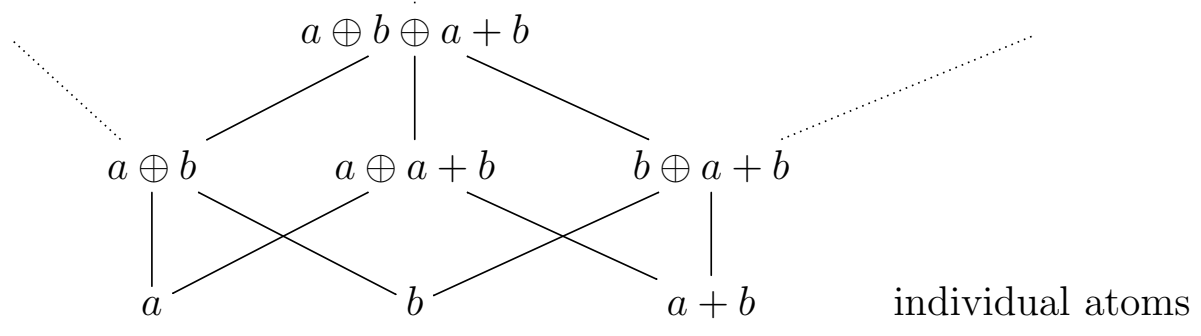

Figure 2: Composite objects are atoms in terms of plurality

'i-part' is a predicate corresponding to the inclusion relation $\leq_{i}$ in the join-semilattice constituted by the (singular and properly plural) entities of type $e$.

$$
\text { i-part' }(x, y) \stackrel{\text { def }}{=} x \oplus y=y
$$

'i-atom' $(x)$ ' means that $x$ is an individual atom, i.e. an atom in that semilattice, i.e. a singular object rather than a (proper) plurality:

$$
\text { i-atom' }(x) \stackrel{\text { def }}{=} \forall y\left(\mathrm{i}-\operatorname{part}^{\prime}(y, x) \rightarrow x=y\right)
$$

Therefore, the books qua composite objects made up of physical and informational parts, as well as those parts themselves, are atoms in this sense, as illustrated in Figure 2. In Figure 2, we have i-atom' $(a)$ and i-atom' $(a+b)$, but $\neg$ i-atom' $(a \oplus b)$. Above, for example in in (8)-(10), I glossed ' $x$ is an atomic individual part of $y$ ' by saying that $x$ is a 'member' of $y$.

The formula in (11) makes use of the relations of physical equivalence and informational equivalence: "phys-equiv"' and "info-equiv" respectively. The relation of physical equivalence holds between (singular) objects $a$ and $b$ if and only if they both have a physical part and the physical part of $a$ is identical to the physical part of $b$. Similarly, objects $a$ and $b$ are informationally equivalent if and only if they both have an informational part and the informational part of $a$ is identical to the informational part of $b$.

For instance, consider the small Dostoyevsky library described at the beginning of Section 2 and depicted in (7) and Figure 1. Here, we have phys-equiv' $\left(v_{1}+N f U, v_{1}+T G\right)$; this is because $v_{1}+N f U$ and $v_{1}+T G$ are physically equivalent, since they have the same physical part: $v_{1}$. However, $\neg$ phys-equiv' $\left(v_{1}+N f U, v_{2}+N f U\right)$.

In what follows, the name of the relation of physical equivalence will often be abbreviated as 'PHYS', and that of informational equivalence as 'INFO'.

$$
\begin{aligned}
& \text { PHYS }=\lambda x \cdot \lambda y \cdot \text { phys-equiv }^{\prime}(x, y) \\
& \mathrm{INFO}=\lambda x \cdot \lambda y \cdot \operatorname{info-equiv}^{\prime}(x, y)
\end{aligned}
$$

Relations like PHYS and INFO I will call 'individuation relations'. ${ }^{6}$ Although I have called these relations of 'equivalence', they are not strictly speaking equivalence relations, because

\footnotetext{
${ }^{6}$ In contrast, the expression 'criterion of individuation' is supposed just to express the pre-theoretical idea 'how things are individuated'. In Section 4.1 the expression 'criterion of individuation' inherits a semitechnical meaning within Asher's (2011) theory of copredication, and in that section I will use the expression in (what I take to be) Asher's intended sense.
} 
(for example) objects that are not even partly physical (i.e. do not have at least one physical part) are physically equivalent to nothing at all, not even themselves; therefore PHYS is not reflexive (but it is transitive and symmetric). ${ }^{7}$

In some of what follows I will express the fact that no two atomic individual parts of a plurality $x$ bear relation $R$ to each other by saying that $x$ is 'not $R$-compressible', or in metalanguage formulae as ' $\neg(R) \operatorname{comp}(x)$ ' — which I will sometimes refer to as a 'compressibility statement'. A definition of the notion of compressibility is given in Definition 1 below.

Definition 1 (Compressibility).

A plurality $x$ is $R$-compressible if and only if there are two distinct atomic individual parts of $x$ that bear relation $R$ to each other.

$$
(R) \operatorname{comp}(x) \stackrel{\text { def }}{=} \exists y \exists z\left(y \neq z \wedge \mathrm{i}-\operatorname{part}^{\prime}(y, x) \wedge \mathrm{i}-\operatorname{part}^{\prime}(z, x) \wedge \mathrm{i}-\operatorname{atom}^{\prime}(y) \wedge \mathrm{i}-\operatorname{atom}^{\prime}(z) \wedge R(y, z)\right)
$$

By way of illustration, note that (12) is PHYS-compressible, because $v_{1}+N f U$ and $v_{1}+T G$ are both atomic individual parts of it, and $v_{1}+N f U$ is physically equivalent to $v_{1}+T G$. In contrast, (13) is not PHYS-compressible, because no two atomic individual parts of it are physically equivalent to each other.

$$
\begin{array}{lll}
v_{1}+N f U \oplus v_{1}+T G \\
v_{1}+N f U \oplus v_{2}+T G
\end{array}
$$

Therefore, (11) can be abridged as shown in (14).

$$
\begin{gathered}
\exists x\left(|x| \geq 3 \wedge{ }^{*} \operatorname{inform}^{\prime}(x) \wedge{ }^{*} \operatorname{book}^{\prime}(x) \wedge{ }^{*} \operatorname{heavy}^{\prime}(x)\right. \\
\wedge \neg((\text { PHYS }) \operatorname{comp}(x) \vee(\text { INFO }) \operatorname{comp}(x)))
\end{gathered}
$$

In the same way, the truth conditions (8) and (9) can be expressed as shown in (15) and (16), respectively.

$$
\begin{aligned}
& \exists x\left(|x| \geq 3 \wedge{ }^{*} \operatorname{book}^{\prime}(x) \wedge{ }^{*} \operatorname{heavy}^{\prime}(x) \wedge \neg(\mathrm{PHYS}) \operatorname{comp}(x)\right) \\
& \exists x\left(|x| \geq 3 \wedge \operatorname{book}^{\prime}(x) \wedge * \operatorname{inform}^{\prime}(x) \wedge \neg(\mathrm{INFO}) \operatorname{comp}(x)\right)
\end{aligned}
$$

The question, then, is how to ensure that the right compressibility statement is built up compositionally in each case. One possible approach, touched on in (Gotham, 2012, §2.4), is to place compressibility statements directly into the interpretations of the open class lexical

\footnotetext{
${ }^{7}$ Or in other words, PHYs is an equivalence relation on the subset of the domain (of singular entities) consisting of things that have at least one physical part, but not on the whole domain.
} 
items, in the manner shown in (17)-(21) below. ${ }^{8}$

$$
\begin{aligned}
& \llbracket b o o k s \rrbracket=\lambda x_{e}{ }^{*} \operatorname{book}^{\prime}(x) \\
& \text { 【informative } \text { in } \rrbracket=\lambda P_{e \rightarrow t} . \lambda x_{e} \cdot{ }^{*} \text { inform }^{\prime}(x) \wedge P(x) \wedge \neg(\mathrm{INFO}) \operatorname{comp}(x) \\
& \text { 【be heavy } y_{p l} \rrbracket=\lambda x_{e} \cdot{ }^{*} \operatorname{heavy}^{\prime}(x) \wedge \neg(\mathrm{PHYS}) \operatorname{comp}(x) \\
& \text { 【be informative } \text { il } \rrbracket=\lambda x_{e} \cdot * \text { inform }^{\prime}(x) \wedge \neg(\mathrm{INFO}) \operatorname{comp}(x) \\
& \llbracket \text { three } \rrbracket=\lambda P_{e \rightarrow t} \cdot \lambda Q_{e \rightarrow t} \cdot \exists x(|x| \geq 3 \wedge P(x) \wedge Q(x))
\end{aligned}
$$

The interpretations of (4)-(6) would then be derived as shown in (22)-(24) below, respectively.

$$
\begin{aligned}
& (21)[(17)][(19)]=\exists x\left(|x| \geq 3 \wedge{ }^{*} \operatorname{book}^{\prime}(x) \wedge{ }^{*} \operatorname{heavy}^{\prime}(x) \wedge \neg(\operatorname{PHYS}) \operatorname{comp}(x)\right) \\
& (21)[(17)][(20)]=\exists x\left(|x| \geq 3 \wedge * \operatorname{book}(x) \wedge *^{*} \text { inform }^{\prime}(x) \wedge \neg(\operatorname{INFO}) \operatorname{comp}(x)\right) \\
& (21)[(18)[(17)]][(19)]=\exists x\left(|x| \geq 3 \wedge *^{*} \operatorname{inform}^{\prime}(x) \wedge * \operatorname{book}^{\prime}(x) \wedge * \operatorname{heavy}^{\prime}(x)\right. \\
& \wedge \neg(\mathrm{PHYS}) \operatorname{comp}(x) \wedge \neg(\mathrm{INFO}) \operatorname{comp}(x))
\end{aligned}
$$

As desired, (22) is the same as (15), (23) is the same as (16), and (24) is equivalent to (14).

Sadly, this approach does not generalize, due to the way in which it requires compressibility statements to be built directly into plural predicates. For example, there is no general principled way for (19) to be derived from either (25) or (26), which would be the obvious candidates for the singular form of 'be heavy'.

$$
\begin{aligned}
& \lambda x_{e} \cdot \operatorname{heavy}(x) \\
& \lambda x_{e} \cdot \operatorname{heavy}(x) \wedge \neg(\text { PHYS }) \operatorname{comp}(x)
\end{aligned}
$$

(26) and (25) are actually equivalent, because the requirement for a singular object not to be physically compressible is trivially satisfied.

One might contend that we can take the plural form (19) to be semantically basic. However, even if we do this the account will not generalize in ways we would like for independent reasons. For example, it would be impossible to make use of any distributivity operator such as is defined in (27) (adapted from Winter and Scha, 2015).

$$
\mathcal{D} \stackrel{\text { def }}{=} \lambda P_{e \rightarrow t} \cdot \lambda x_{e} \cdot \forall y\left(\left(\mathrm{i}-\operatorname{part}^{\prime}(y, x) \wedge \text { i-atom }{ }^{\prime}(y)\right) \rightarrow P(y)\right)
$$

It is widely agreed that a distributivity operator of this kind is needed in certain cases. For example, it is required to derive the interpretation of (28) on which there are three physically distinct books, and each one of them is either heavy or tattered (Winter and Scha, 2015), even if the predicates 'heavy' and 'tattered' themselves are distributive (as they are taken to be here for simplicity's sake).

(28) Three books are heavy or tattered.

\footnotetext{
${ }^{8}$ This point was also raised by an anonymous reviewer.
} 
Assuming the interpretation for the disjoined VP as shown in (29) below, the result of distributivizing it would be as shown in (30).

$$
\begin{aligned}
& \lambda x_{e} \cdot\left({ }^{*} \operatorname{heavy}^{\prime}(x) \wedge \neg(\text { PHYS }) \operatorname{comp}(x)\right) \vee\left({ }^{*} \operatorname{tattered}^{\prime}(x) \wedge \neg(\operatorname{PHYS}) \operatorname{comp}(x)\right) \\
& =\lambda x_{e} \cdot\left({ }^{*} \operatorname{heavy}^{\prime}(x) \vee * \operatorname{tattered}^{\prime}(x)\right) \wedge \neg(\operatorname{PHYS}) \operatorname{comp}(x) \\
& \begin{array}{r}
\mathcal{D}[(29)]=\lambda x_{e} \cdot \forall y\left(( \text { i-part } ^ { \prime } ( y , x ) \wedge \mathrm { i } - \operatorname { a t o m } ^ { \prime } ( y ) ) \rightarrow \left(\left({ }^{*} \operatorname{heavy}^{\prime}(y) \vee * \operatorname{tattered}^{\prime}(y)\right)\right.\right. \\
\wedge \neg(\operatorname{PHYS}) \operatorname{comp}(y))) \\
=\lambda x_{e} \cdot \forall y\left(\left(\mathrm{i}-\operatorname{part}^{\prime}(y, x) \wedge \mathrm{i}-\operatorname{atom}^{\prime}(y)\right) \rightarrow\left(\operatorname{heavy}^{\prime}(y) \vee \operatorname{tattered}^{\prime}(y)\right)\right)
\end{array}
\end{aligned}
$$

The effect of the distributivity operator has been to eliminate the compressibility statement because, again, singular objects trivially satisfy the requirement of not being physically compressible. On these assumptions, our interpretation of (28) would then end up being as shown in (31).

$$
\begin{aligned}
& (21)[(17)][(30)]=\exists x\left(|x| \geq 3 \wedge{ }^{*} \operatorname{book}^{\prime}(x) \wedge \forall y\left(\left(\mathrm{i}-\operatorname{part}^{\prime}(y, x) \wedge \text { i-atom }{ }^{\prime}(y)\right)\right.\right. \\
& \left.\left.\rightarrow\left(\operatorname{heavy}^{\prime}(y) \vee \text { tattered }^{\prime}(y)\right)\right)\right)
\end{aligned}
$$

(31) has no compressibility statement, and as such is subject to the problems with naïve mereological approaches to copredication outlined in Section 2. To summarize: whether we take distributivity to be fully lexically determined or the result of some additional process, the simple approach embodied in (17)-(21) is inadequate to derive appropriate compressibility statements in at least some cases, because pluralization/distributivization would have the effect of passing the compressibility statements onto singular objects, which trivially satisfy them.

With this in mind, I instead propose to split the formation of a compressibility statement into two parts: predicates contribute the individuation relations, while determiners combine those individuation relations into the actual statement of non-compressibility. ${ }^{9}$ The basics of that approach will be described in Section 3.1.2.

\subsubsection{A simplified version of the compositional system}

For the rest of the paper, it will be useful to represent (14) by the equivalent form shown in (32) below.

$$
\exists x\left(|x| \geq 3 \wedge{ }^{*} \operatorname{heavy}^{\prime}(x) \wedge{ }^{*} \operatorname{book}^{\prime}(x) \wedge *^{*} \operatorname{inform}^{\prime}(x) \wedge \neg(\text { PHYS } \sqcup \mathrm{INFO}) \operatorname{comp}(x)\right)
$$

$\sqcup$ is the join operation that can apply in any boolean algebra, such as is formed for example by the set of inhabitants of type $e \rightarrow(e \rightarrow t)$ (Keenan and Faltz, 1985) (and $\sqcap$ is the corresponding meet operation). It can be implemented as in the 'generalized conjunction' approach put forward by Partee and Rooth (1983), because in that approach $e \rightarrow(e \rightarrow t)$ is a 'conjoinable type' as defined in (33).

\footnotetext{
${ }^{9}$ This leaves open the question of what happens with predicates that don't (obviously) contribute individuation relations, for example in a sentence such as 'John requested three books'. See (Gotham, 2014, §3.3) for some discussion.
} 
(33) $t$ is a conjoinable type.

For all $a$ and $b$, if $b$ is a conjoinable type then $a \rightarrow b$ is a conjoinable type.

The recursive definition of generalized disjunction is given in (34). The definitions give in (33) and (34) are adapted from equivalent ones given by Partee and Rooth (1983).

$$
\begin{aligned}
& \text { If } X: t \text { and } Y: t \text {, then } X \sqcup Y \stackrel{\text { def }}{=} X \vee Y \text {. } \\
& \text { If } X: a \rightarrow b \text { and } Y: a \rightarrow b \text {, then } X \sqcup Y \stackrel{\text { def }}{=} \lambda v_{a}(X(v) \sqcup Y(v)) \text {. }
\end{aligned}
$$

So for example, PHYS $\sqcup$ INFO has the interpretation shown below, which makes (14) equivalent to $(32)$.

$$
\begin{aligned}
\text { PHYS } \sqcup \mathrm{INFO} & =\lambda x_{e}\left(\lambda y_{e}\left(\operatorname{phys-equiv}^{\prime}(x, y)\right)\right) \sqcup \lambda x_{e}\left(\lambda y_{e}\left(\operatorname{info-equiv}^{\prime}(z, v)\right)\right) \\
& =\lambda v_{e}\left(\lambda y_{e}\left(\operatorname{phys-equiv}^{\prime}(v, y)\right) \sqcup \lambda y_{e}\left(\operatorname{info-equiv}^{\prime}(v, y)\right)\right) \\
& =\lambda v_{e}\left(\lambda u_{e}\left(\operatorname{phys-equiv}^{\prime}(v, u) \sqcup \operatorname{info-equiv}^{\prime}(v, u)\right)\right) \\
& =\lambda v_{e}\left(\lambda u_{e}\left(\operatorname{phys-equiv}^{\prime}(v, u) \vee \operatorname{info-equiv}^{\prime}(v, u)\right)\right)
\end{aligned}
$$

In order to implement the ideas described as the end of Section 3.1.1, I propose to use product types for interpretations, as encapsulated in the provisional lexical entries given in (35)-(39) below (these will be updated in Section 3.2.1). In each case, a property-denoting expression also carries an individuation relation as part of its meaning.

$$
\begin{aligned}
& \llbracket t a b l e \rrbracket=\lambda x_{e}\left\langle\operatorname{table}^{\prime}(x), \text { PHYS }\right\rangle \\
& \llbracket b o o k \rrbracket=\lambda x_{e}\left\langle\operatorname{book}^{\prime}(x), \text { PHYS } \sqcap \mathrm{INFO}\right\rangle \\
& \llbracket b o o k s \rrbracket=\lambda y_{e}\left\langle{ }^{*} \operatorname{book}^{\prime}(y), \quad \text { PHYS } \sqcap \mathrm{INFO}\right\rangle \\
& \llbracket \text { be heavy } p \rrbracket=\lambda y_{e}\left\langle{ }^{*} \operatorname{heavy}^{\prime}(y) \text {, PHYs }\right\rangle \\
& \text { 【be informative } p l \rrbracket=\lambda y_{e}\left\langle{ }^{*} \operatorname{inform}^{\prime}(y), \text { INFO }\right\rangle
\end{aligned}
$$

$\sqcap$ is the generalized conjunction operator corresponding to the generalized disjunction operator defined above. Its inclusion in the lexical entries for 'book(s)' allows books, unlike (say) tables, to be individuated in more than one way; describing how this variable individuation is achieved compositionally is the aim of the present section. This is the extent to which the ability to support copredication is marked in the lexical entries for nouns. PHYS $\sqcap$ INFO means that the lexical entry for 'book' includes the relation that is the generalized conjunction of the relations of physical and informational equivalence. Importantly, no matching between function and argument with respect to these relations is required to take place during composition.

The expressions shown in (35)-(39) are of type $e \rightarrow(t \times \mathcal{R})$, where $\mathcal{R}$ is an abbreviation of $e \rightarrow(e \rightarrow t) .(t \times \mathcal{R})$ is a product type, and so inhabitants of this type will be ordered pairs $\langle a, b\rangle$, where $a$ is a truth value - standard sentence extensional meaning - and $b$ is an individuation relation. As per conventional usage, $\pi_{1}(\langle a, b\rangle)=a$ and $\pi_{2}(\langle a, b\rangle)=b$ : the "first projection' of $\langle a, b\rangle$ and the 'second projection' of $\langle a, b\rangle$, respectively. In each case, there is a simple method for going back from the interpretation shown above to a meaning of the type conventionally assumed for the lexical item. For instance, $\lambda y \cdot \pi_{1}(P(y))$, where $P=\llbracket b o o k \rrbracket$, is 
$\lambda y \cdot \operatorname{book}^{\prime}(y)$, as shown below.

$$
\begin{aligned}
\lambda y \cdot \pi_{1}(\llbracket b o o k \rrbracket(y)) & =\lambda y \cdot \pi_{1}\left(\lambda x_{e}\left\langle\operatorname{book}^{\prime}(x), \text { PHYS } \sqcap \operatorname{INFO}\right\rangle(y)\right) \\
& =\lambda y \cdot \pi_{1}\left(\left\langle\operatorname{book}^{\prime}(y), \text { PHYS } \sqcap \operatorname{INFO}\right\rangle\right) \\
& =\lambda y \cdot \operatorname{book}^{\prime}(y)
\end{aligned}
$$

Note that now it is a simple matter to pluralize denotational content and leave the individuation relation unaffected. For example, (37) can be derived from (36) via a simple pluralization operator.

It is also possible now to access the individuation relations associated with interpretations. For example, $\pi_{2}(\llbracket b o o k \rrbracket(y))$ is as shown below.

$$
\begin{aligned}
\pi_{2}(\llbracket b o o k \rrbracket(y)) & =\pi_{2}\left(\lambda x_{e} \cdot\left\langle\operatorname{book}^{\prime}(x), \text { PHYS } \sqcap \operatorname{INFO}\right\rangle(y)\right) \\
& =\pi_{2}\left(\left\langle\operatorname{book}^{\prime}(y), \text { PHYS } \sqcap \operatorname{INFO}\right\rangle\right) \\
& =\text { PHYS } \sqcap \operatorname{INFO}
\end{aligned}
$$

Accessing and exploiting individuation relations, so as to be able to form appropriate compressibility statements, is the role of determiners in this system. An example is given by

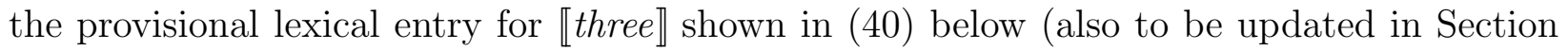
$3.2 .1)$.

$$
\begin{aligned}
\lambda P_{e \rightarrow(t \times \mathcal{R}) \cdot} \cdot \lambda Q_{e \rightarrow(t \times \mathcal{R})} & \left\langle\exists x\left(|x| \geq 3 \wedge \pi_{1}(P(x)) \wedge \pi_{1}(Q(x)) \wedge \neg\left(\pi_{2}(P(x)) \sqcup \pi_{2}(Q(x))\right) \operatorname{comp}(x)\right),\right. \\
& \left.\pi_{2}(P(x)) \sqcap \pi_{2}(Q(x))\right\rangle
\end{aligned}
$$

\section{Some examples}

Let us see how the lexical entries given above conspire to generate interpretations for (4) and (6). We want (4) to require only that the books involved be physically distinct, but we want (6) to require that the books involved be both informationally and physically distinct, as reflected in (10) and (32).

In order to obtain the interpretation of 'three books' we apply (40) to (37). With $P=$

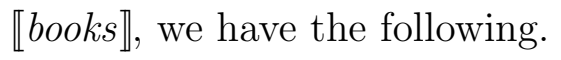

$$
\begin{aligned}
\pi_{1}(P(x)) & =\pi_{1}(\llbracket \text { books } \rrbracket(x)) \\
& =\pi_{1}\left(\lambda y_{e}\left\langle{ }^{*} \operatorname{book}^{\prime}(y), \text { PHYS } \sqcap \mathrm{INFO}\right\rangle(x)\right) \\
& =\pi_{1}\left(\left\langle\operatorname{book}^{\prime}(x), \text { PHYS } \sqcap \operatorname{INFO}\right\rangle\right) \\
& =* \operatorname{book}^{\prime}(x) \\
\pi_{2}(P(x)) & =\pi_{2}(\llbracket b o o k s \rrbracket(x)) \\
& =\pi_{2}\left(\lambda y_{e}\left\langle * \operatorname{book}^{\prime}(y), \text { PHYS } \sqcap \operatorname{INFO}\right\rangle(x)\right) \\
& =\pi_{2}\left(\left\langle * \operatorname{book}^{\prime}(x), \text { PHYS } \sqcap \operatorname{INFO}\right\rangle\right) \\
& =\text { PHYS } \sqcap \operatorname{INFO}
\end{aligned}
$$




$$
\begin{aligned}
& \therefore \llbracket \text { three books } \rrbracket=\lambda Q_{e \rightarrow(t \times \mathcal{R})} \\
& \left\langle\exists x\left(|x| \geq 3 \wedge{ }^{*} \operatorname{book}^{\prime}(x) \wedge \pi_{1}(Q(x)) \wedge \neg\left((\text { PHYS } \sqcap \mathrm{INFO}) \sqcup \pi_{2}(Q(x))\right) \operatorname{comp}(x)\right),\right. \\
& \left.\quad(\mathrm{PHYS} \sqcap \mathrm{INFO}) \sqcap \pi_{2}(Q(x))\right\rangle
\end{aligned}
$$

Note that the compressibility statement of the whole sentence depends on both arguments to the determiner, and hence is not finalized at this stage.

In order to obtain the interpretation of (4) we apply (41) to (38). With $Q=\llbracket b e$ heavy we have the following:

$$
\begin{aligned}
\pi_{1}(Q(x)) & =\pi_{1}\left(\llbracket \text { be heavy }_{p l} \rrbracket(x)\right) \\
& =\pi_{1}\left(\lambda y_{e}\left\langle{ }^{*} \operatorname{heavy}^{\prime}(y), \text { PHYS }\right\rangle(x)\right) \\
& =\pi_{1}\left(\left\langle\operatorname{heavy}^{\prime}(x), \text { PHYS }\right\rangle\right) \\
& =\text { heavy }^{\prime}(x) \\
\pi_{2}(Q(x)) & =\pi_{2}\left(\llbracket \text { be heavy }_{p l} \rrbracket(x)\right) \\
& =\pi_{2}\left(\lambda y_{e}\left\langle{ }^{*} \operatorname{heavy}^{\prime}(y), \text { PHYS }\right\rangle(x)\right) \\
& =\pi_{2}\left(\left\langle * \operatorname{heavy}^{\prime}(x), \text { PHYS }\right\rangle\right) \\
& =\text { PHYS }
\end{aligned}
$$

$\therefore \llbracket$ three books are heavy $\rrbracket=(41)[(38)]$

$$
\begin{aligned}
=\langle & \left\langle x\left(|x| \geq 3 \wedge{ }^{*} \operatorname{book}^{\prime}(x) \wedge{ }^{*} \operatorname{heavy}^{\prime}(x) \wedge \neg((\text { PHYS } \sqcap \mathrm{INFO}) \sqcup \mathrm{PHYS}) \operatorname{com} p(x)\right),\right. \\
& (\text { PHYS } \sqcap \mathrm{INFO}) \sqcap \mathrm{PHYS}\rangle
\end{aligned}
$$

Because of the boolean equalities shown in (43-a)-(43-b), (42) can be simplified to (44).

$$
\begin{aligned}
& \text { a. } \quad(A \sqcap B) \sqcup B=B \\
& \text { b. } \quad(A \sqcap B) \sqcap B=A \sqcap B \\
& \left\langle\exists x\left(|x| \geq 3 \wedge{ }^{*} \operatorname{book}^{\prime}(x) \wedge{ }^{*} \operatorname{heavy}^{\prime}(x) \wedge \neg(\text { PHYS }) \operatorname{comp}(x)\right), \text { PHYS } \sqcap \text { INFO }\right\rangle
\end{aligned}
$$

The first projection of (44) is identical to (15), as desired. It says is that there is a plurality of three heavy books, and this plurality is not physically compressible. These are the right truth conditions for (4) - they are the truth conditions described in (8).

It should now be clear why the lexical entry for 'books' in (37) took the form that it did, with PHYS $\sqcap$ INFO. By requiring the determiner to combine the individuation relations from

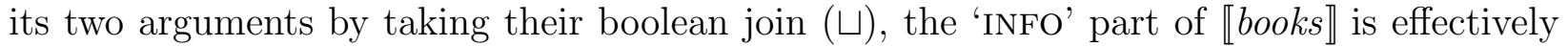
cancelled when it is combined (only) with a physical predicate like «be heavy $y_{p l} \rrbracket$ in (4).

In the case of copredication, things are different. To see this in the case of (6), we need to add an entry for attributive 'informative' to the toy lexicon:

$$
\llbracket \text { informative }_{p l} \rrbracket=\lambda P_{e \rightarrow(t \times \mathcal{R})} \cdot \lambda z_{e}\left\langle\left({ }^{*} \operatorname{inform}^{\prime}(z) \wedge \pi_{1}(P(z))\right), \pi_{2}(P(z)) \sqcup \mathrm{INFO}\right\rangle
$$


Doing so means that we get the interpretations shown below.

$$
\begin{aligned}
& \llbracket \text { informative books } \rrbracket=\llbracket \text { informative }_{p l} \rrbracket(\llbracket \text { books } \rrbracket) \\
& =\lambda y_{e}\left\langle * \operatorname{inform}^{\prime}(y) \wedge{ }^{*} \operatorname{book}^{\prime}(y),(\text { PHYS } \sqcap \mathrm{INFO}) \sqcup \mathrm{INFO}\right\rangle \\
& =\lambda y_{e}\left\langle * \operatorname{inform}^{\prime}(y) \wedge{ }^{*} \operatorname{book}^{\prime}(y), \text { INFO }\right\rangle
\end{aligned}
$$

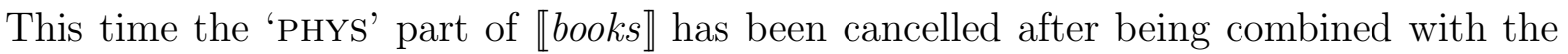
physical predicate 【informative $p l \rrbracket$.

Applying (40) to (45), we obain the interpretation of 'three informative books' shown in (46).

$$
\begin{aligned}
\lambda Q_{e \rightarrow(t \times \mathcal{R})}\langle\exists x(|x| & \geq 3 \wedge{ }^{*} \operatorname{inform}^{\prime}(x) \wedge * \operatorname{book}^{\prime}(x) \wedge \pi_{1}(Q(x)) \\
\wedge & \left.\left.\neg\left(\operatorname{INFO} \sqcup \pi_{2}(Q(x))\right) \operatorname{comp}(x)\right), \text { INFO } \sqcap \pi_{2}(Q(x))\right\rangle
\end{aligned}
$$

Note how the compressibility statement at this stage is different from that of (41). Therefore, if we apply (46) to (38) then we obtain (47) as the interpretation of (6).

$$
\begin{aligned}
& \left\langle\exists x\left(|x| \geq 3 \wedge{ }^{*} \operatorname{inform}^{\prime}(x) \wedge{ }^{*} \operatorname{book}^{\prime}(x) \wedge{ }^{*} \operatorname{heavy}^{\prime}(x) \wedge \neg(\text { INFO } \sqcup \text { PHYS }) \operatorname{comp}(x)\right),\right. \\
& \text { INFO } \sqcap \text { PHYS }\rangle
\end{aligned}
$$

The first projection of (47) is the same as (32), as desired. It says is that there is a plurality of three informative, heavy books, and this plurality is neither informationally nor physically compressible. These are the right truth conditions for (6) - they are the truth conditions described in (10).

So from these examples we can see how lexical entries can combine to generate the appropriate compressibility statements for a non-copredication sentence (4) and a copredication sentence (6). The key elements to the account are that predicates contain individuation relations, and determiners access and exploit those individuation relations to form compressibility statements. ${ }^{10}$

\subsection{Generalizing the system}

\subsubsection{Keeping track of individuation relations}

The account given in Section 3.1.2 is too simple, however. The problem is that it only makes it possible to 'store' one individuation relation in any interpretation, in the sense that INFO is 'stored' in (39), for example. But for full generality we have to be able to keep track of different individuation relations for different arguments to any predicate that takes more than one argument. Take a verb like 'pick up', for example. We want to be able to state that this verb connects the PHYS individuation relation to its object, so as to be able to require that the three books in (48) be physically (although not necessarily informationally) distinct from each other.

\footnotetext{
${ }^{10}$ For discussion of existential sentences like 'there are three books', see (Gotham, 2014, §3.3).
} 
John picked up three books.

At the same time, we do not necessarily want to make the same imposition on its subject position. Similarly, we want to be able to link the object argument of a verb like 'master' with the INFO individuation relation, so as to be able to require that the three books in (49) be informationally (although not necessarily physically) distinct from each other.

John mastered three books.

And for a copredication sentence like (50), we want to be able to require that the three books in question are both physically and informationally distinct from each other.

(50) John mastered three heavy books.

What is needed is something like the schematic entry shown in (51). ${ }^{11}$

$$
\llbracket p i c k u p \rrbracket=\lambda x_{e} \cdot \lambda y_{e}\left\langle\operatorname{pick-up}^{\prime}(y, x), \begin{array}{l}
x \rightsquigarrow \mathrm{PHYS} \\
y \rightsquigarrow \mathrm{ANI}
\end{array}\right\rangle
$$

The $\rightsquigarrow$ symbol here is simply meant to indicate that there is some connection between the variable shown and the individuation relation shown. Specifying just what that connection is is the purpose of the current section.

To do this we are going to need to make further use of the algebraic properties of the domain of type $e \rightarrow(e \rightarrow t)$. Specifically, in addition to the meet $\square$ and join $\sqcup$ operations in this algebra that we are already using, we need to make use of the partial order $\sqsubseteq$.

Like $\sqcap$ and $\sqcup$, for our purposes $\sqsubseteq$ can be given a recursive definition in terms of functions, as shown in (52) below. It is, in effect, a form of generalized entailment.

$$
\begin{aligned}
& \text { If } X: t \text { and } Y: t \text {, then } X \sqsubseteq Y \stackrel{\text { def }}{=} X \rightarrow Y \text {. } \\
& \text { If } X: a \rightarrow b \text { and } Y: a \rightarrow b \text {, then } X \sqsubseteq Y \stackrel{\text { def }}{=} \forall v_{a}(X(v) \sqsubseteq Y(v)) .
\end{aligned}
$$

It follows that in the domain for the type that we are interested in, $e \rightarrow(e \rightarrow t)$, we have $A \sqsubseteq B=\forall x \forall y(A(x, y) \rightarrow B(x, y))$.

As this is a boolean algebra, the following proofs hold: ${ }^{12}$

$$
\begin{array}{ll}
\text { a. } & \vdash(A \sqcap B) \sqsubseteq A \\
\text { b. } & \vdash(A \sqcap B) \sqsubseteq B \\
\text { c. } & A \sqsubseteq B, A \sqsubseteq C \vdash A \sqsubseteq(B \sqcap C) \\
\text { a. } & \vdash A \sqsubseteq(A \sqcup B) \\
\text { b. } & \vdash B \sqsubseteq(A \sqcup B) \\
\text { c. } & A \sqsubseteq(B \sqcup C) \vdash A \sqsubseteq B, A \sqsubseteq C
\end{array}
$$

\footnotetext{
${ }^{11}$ By stipulation I have chosen to link the subject of 'pick up' with ANI, the relation of animate equivalence, which holds between objects $a$ and $b$ if and only if they both have an animate part and the animate part of $a$ is identical to the animate part of $b$. It will play no role in this paper and any other individuation relation could be chosen without affecting the main points.

${ }^{12} \mathrm{As}$ in sequent calculus a comma to the left of the turnstile indicates conjunction and to the right of the turnstile, disjunction.
} 
I am now in a position to state the lexical entry for 'pick up':

$$
\llbracket \text { pick up }=\lambda x_{e} \cdot \lambda y_{e}\left\langle\text { pick-up }^{\prime}(y, x), \lambda f_{e \rightarrow \mathcal{R}} \cdot f(y) \sqsubseteq \mathrm{ANI} \wedge f(x) \sqsubseteq \mathrm{PHYS}\right\rangle
$$

The lexical entry shown in (55) is of type $e \rightarrow(e \rightarrow(t \times((e \rightarrow \mathcal{R}) \rightarrow t)))$. I will henceforth abbreviate $t \times((e \rightarrow \mathcal{R}) \rightarrow t)$ as $T$, as this is the (extensional) type of sentence meaning. (55) is therefore of type $e \rightarrow(e \rightarrow T)$. The second member of the ordered pair shown in (55) is no longer simply an individuation relation as in Section 3.1, but rather (the characteristic function of ) a set of functions of type $e \rightarrow \mathcal{R}$, each of which maps $x$ to some relation $R_{1}$ such that $R_{1} \sqsubseteq$ PHYS and maps $y$ to some relation $R_{2}$ such that $R_{2} \sqsubseteq$ ANI. In what follows I will sometimes refer to this set of functions as a 'construction'.

\section{Definition 2 (Construction).}

If $e$ is an expression such that $\llbracket e \rrbracket=\lambda \ldots\langle a, b\rangle$ of a type terminating in $T$, the construction of $e$ is $b$.

The reason that the partial order $\sqsubseteq$ has been chosen to fulfil the role of $\rightsquigarrow$ in (51) is that this formulation allows constructions to be combined monotonically. So for example, we want it to be the case that if there are requirements that $x$ be mapped to PHYS and also that $x$ be mapped to INFO, then $x$ is mapped to PHYS $\sqcap$ INFO. (53-c) guarantees this, as instantiated in (56) below.

$$
f(x) \sqsubseteq \mathrm{PHYS}, f(x) \sqsubseteq \mathrm{INFO} \vdash f(x) \sqsubseteq(\mathrm{PHYS} \sqcap \mathrm{INFO})
$$

The target truth conditions for (49) and (50) are shown below in (57) and (58), respectively. The definition of the (slightly non-standard) star operator for two-place predicates ${ }_{2}^{*}$ that I am using is shown in (59). ${ }^{13}$

$$
\begin{aligned}
& \exists x\left(|x| \geq 3 \wedge{ }^{*} \operatorname{book}^{\prime}(x) \wedge{ }_{2}^{*} \operatorname{master}^{\prime}\left(j^{\prime}, x\right) \wedge \neg(\operatorname{INFO}) \operatorname{comp}(x)\right) \\
& \exists x\left(|x| \geq 3 \wedge{ }^{*} \operatorname{heavy}^{\prime}(x) \wedge \operatorname{book}^{\prime}(x) \wedge{ }_{2}^{*} \text { master }\left(j^{\prime}, x\right) \wedge \neg(\text { PHYS } \sqcup \mathrm{INFO}) \operatorname{comp}(x)\right) \\
& { }_{2}^{*} R(x, y) \stackrel{\text { def }}{=} *\left(\lambda v_{e} \cdot R(x, v)\right)(y) \vee *\left(\lambda z_{e} \cdot R(z, y)\right)(x)
\end{aligned}
$$

In practice, I will omit the subscript ' 2 ' where there is no risk of confusion. Note that oneplace and two-place pluralization can easily be defined, as shown in (60) and (61) respectively. From now on I will assume pluralized forms.

$$
\begin{aligned}
& \lambda P_{e \rightarrow T}\left\langle^{*}\left(\pi_{1}(P)\right), \pi_{2}(P)\right\rangle \\
& \lambda R_{e \rightarrow(e \rightarrow T)}\left\langle{ }_{2}^{*}\left(\pi_{1}(R)\right), \pi_{2}(R)\right\rangle
\end{aligned}
$$

In the light of the changes made above, revised versions of the lexical entries given in (35)-(39) are shown in (62)-(66) respectively below. These are all of type $e \rightarrow T$.

\footnotetext{
${ }^{13}$ This is slightly different to the double star 'cumulation' operator sometimes seen, e.g. in (Beck and Sauerland, 2000), in that it is more restrictive. The difference is probably not crucial.
} 


$$
\begin{aligned}
& \llbracket \text { table } \rrbracket=\lambda x_{e}\left\langle\operatorname{table}^{\prime}(x), \lambda f_{e \rightarrow \mathcal{R}} \cdot f(x) \sqsubseteq \mathrm{PHYS}\right\rangle \\
& \llbracket \text { book } \rrbracket=\lambda x_{e}\left\langle\operatorname{book}^{\prime}(x), \lambda f_{e \rightarrow \mathcal{R}} \cdot f(x) \sqsubseteq(\mathrm{PHYS} \sqcap \mathrm{INFO})\right\rangle \\
& \llbracket \text { books } \rrbracket=(60)[(63)]=\lambda x_{e}\left\langle{ }^{*} \operatorname{book}^{\prime}(x), \lambda f_{e \rightarrow \mathcal{R}} \cdot f(x) \sqsubseteq(\mathrm{PHYS} \sqcap \mathrm{INFO})\right\rangle \\
& \llbracket \text { be heavy } \rrbracket=\lambda x_{e}\left\langle{ }^{*} \operatorname{heavy}^{\prime}(x), \lambda f_{e \rightarrow \mathcal{R}} \cdot f(x) \sqsubseteq \mathrm{PHYS}\right\rangle \\
& \llbracket \text { be informative } e_{p l} \rrbracket=\lambda x_{e}\left\langle{ }^{*}{ }^{\operatorname{inform}}(x), \lambda f_{e \rightarrow \mathcal{R}} \cdot f(x) \sqsubseteq \mathrm{INFO}\right\rangle
\end{aligned}
$$

We now face the question of how we are going to access individuation relations, which needs to be done in order to build compressibility statements. In Section 3.1 this was achieved simply with the use of $\pi_{2}$ (e.g. in (40)), but that will no longer work because of the complication of lexical entries that has just been made.

In order to do this, let us first look at a version of (64) from which all information not relevant to construction has been removed. ${ }^{14}$ This is shown in (67).

$$
\lambda x_{e} \cdot \lambda f_{e \rightarrow \mathcal{R}} \cdot f(x) \sqsubseteq(\mathrm{PHYS} \sqcap \mathrm{INFO})
$$

What we want to do is to get at the the 'PHYS $\square$ INFO' in (67), i.e. the individuation relation associated with the abstracted variable. In order to do this:

- We note that for an arbitrary object $o,(67)[o]$ is (the characteristic function of) the set of functions $f$ such that $f(o) \sqsubseteq$ (PHYS $\sqcap$ INFO).

- We map this set of functions to the set of its values with respect to $o$, and take the least upper bound of that set, which will be PHYS $\sqcap$ INFO.

Formally, we use the function $\Omega$, of type $(e \rightarrow((e \rightarrow \mathcal{R}) \rightarrow t)) \rightarrow \mathcal{R}$. Its definition is given in (68). ${ }^{15}$

$$
\Omega(A) \stackrel{\text { def }}{=} \bigsqcup\left\{R: \exists x_{e} \exists f_{e \rightarrow \mathcal{R}}(A(x)(f) \wedge f(x)=R)\right\}
$$

The $\Omega$ function can now be used to access particular individuation relations within interpretations. For expressions of type $e \rightarrow T$ I will use the function $\Omega_{1}$, of type $(e \rightarrow T) \rightarrow \mathcal{R}$, as defined in (69).

$$
\Omega_{1}(A) \stackrel{\text { def }}{=} \Omega\left(\lambda v_{e} \cdot \pi_{2}(A(v))\right)
$$

$\Omega_{1}(\llbracket b o o k s \rrbracket)$ is therefore PHYS $\sqcap$ INFO, as can be seen from the working in (70) below.

$$
\begin{aligned}
& \Omega_{1}(\llbracket b o o k s \rrbracket)=\Omega\left(\lambda v_{e} \cdot \pi_{2}(\llbracket b o o k s \rrbracket(v))\right) \\
& =\Omega\left(\lambda v_{e} \cdot \pi_{2}\left(\lambda y_{e}\left\langle{ }^{*} \operatorname{book}^{\prime}(y), \lambda f_{e \rightarrow \mathcal{R}} \cdot f(y) \sqsubseteq(\mathrm{PHYS} \sqcap \mathrm{INFO})\right\rangle(v)\right)\right) \\
& =\Omega\left(\lambda v_{e} \cdot \pi_{2}\left(\left\langle{ }^{*} \operatorname{book}^{\prime}(v), \lambda f_{e \rightarrow \mathcal{R}} \cdot f(v) \sqsubseteq(\mathrm{PHYS} \sqcap \mathrm{INFO})\right\rangle\right)\right) \\
& =\Omega\left(\lambda v_{e} \cdot \lambda f_{e \rightarrow \mathcal{R}} \cdot f(v) \sqsubseteq(\mathrm{PHYS} \sqcap \mathrm{INFO})\right) \\
& =\bigsqcup\left\{R: \exists x_{e} \exists f_{e \rightarrow \mathcal{R}}((f(x) \sqsubseteq(\mathrm{PHYS} \sqcap \mathrm{INFO})) \wedge f(x)=R)\right\} \\
& =\bigsqcup\{R: R \sqsubseteq(\mathrm{PHYS} \sqcap \mathrm{INFO})\} \\
& =\text { PHYS } \sqcap \mathrm{INFO}
\end{aligned}
$$

\footnotetext{
${ }^{14}(67)=\lambda x_{e} \cdot \pi_{2}((64)(x))$.

${ }^{15} \mathrm{I}$ use $\bigsqcup A$ rather than $\bigvee A$ to indicate the least upper bound of $A$, because I have been using $\sqcup$ rather than $\vee$ to indicate the join operation.
} 
For expressions of type $e \rightarrow(e \rightarrow T)$, such as (55), we can define the function $\Omega_{2}$ as shown in (71).

$$
\Omega_{2}(R) \stackrel{\text { def }}{=} \Omega\left(\lambda v_{e} \cdot \lambda f_{e \rightarrow \mathcal{R}} \cdot \exists z\left(\pi_{2}(R(v)(z))(f)\right)\right)
$$

The idea is to get the criterion of individuation associated with the most oblique argument of the verb. $\Omega_{2}(\llbracket p i c k u p \rrbracket)$ is therefore PHYS, as can be seen from the working in (73).

$$
\begin{aligned}
& \Omega_{2}(\llbracket \text { pick up } \rrbracket)=\Omega\left(\lambda v_{e} \cdot \lambda f_{e \rightarrow \mathcal{R}} \cdot \exists z\left(\pi_{2}(\llbracket p i c k-u p \rrbracket(v)(z))(f)\right)\right) \\
&= \Omega\left(\lambda v _ { e } \cdot \lambda f _ { e \rightarrow \mathcal { R } } \cdot \exists z \left(\pi _ { 2 } \left(\lambda x _ { e } \cdot \lambda y _ { e } \left\langle\text { pick-up' }^{\prime}(y, x),\right.\right.\right.\right. \\
&\left.\left.\left.\left.\lambda g_{e \rightarrow \mathcal{R}}(g(y) \sqsubseteq \mathrm{ANI} \wedge g(x) \sqsubseteq \mathrm{PHYS})\right\rangle(v)(z)\right)(f)\right)\right) \\
&=\Omega\left(\lambda v_{e} \cdot \lambda f_{e \rightarrow \mathcal{R}} \cdot \exists z\left(\pi_{2}\left(\left\langle\text { pick-up }^{\prime}(z, v),(f(z) \sqsubseteq \mathrm{ANI} \wedge f(v) \sqsubseteq \mathrm{INFO})\right\rangle\right)\right)\right) \\
&= \Omega\left(\lambda v_{e} \cdot \lambda f_{e \rightarrow \mathcal{R}} \cdot \exists z(f(z) \sqsubseteq \mathrm{ANI} \wedge f(v) \sqsubseteq \mathrm{PHYS})\right) \\
&= \bigsqcup\left\{R: \exists x_{e} \exists f_{e \rightarrow \mathcal{R}}(\exists z(f(z) \sqsubseteq \mathrm{ANI} \wedge f(x) \sqsubseteq \mathrm{PHYS}) \wedge f(x)=R)\right\} \\
&= \bigsqcup\{R: R \sqsubseteq \mathrm{PHYS}\} \\
&= \text { PHYS }
\end{aligned}
$$

\subsubsection{Implementation}

We now have the formal apparatus in place to define lexical entries for determiners that will, in combination with those already given for predicates, derive the appropriate compressibility statements, and hence the right truth conditions, for copredication and non-copredication sentences. For instance, the final version of the lexical entry for the determiner 'three' is shown in (73).

$$
\begin{aligned}
& \llbracket \text { three } \rrbracket= \\
& \begin{aligned}
\lambda A_{e \rightarrow T} . \lambda B_{e \rightarrow T}\langle & \left\langle x\left(|x| \geq 3 \wedge \pi_{1}(A(x)) \wedge \pi_{1}(B(x)) \wedge \neg\left(\Omega_{1}(A) \sqcup \Omega_{1}(B)\right) \operatorname{comp}(x)\right),\right. \\
\qquad & \left.\lambda h_{e \rightarrow \mathcal{R}} \cdot \exists v\left(\pi_{1}(A(v)) \wedge \pi_{2}(A(v))(h) \wedge \pi_{2}(B(v))(h)\right)\right\rangle
\end{aligned}
\end{aligned}
$$

Since it has already been established (in (70)) that $\Omega_{1}(\llbracket$ books $\rrbracket)=$ PHYS $\sqcap$ INFO, we can see that $\llbracket$ three books $\rrbracket$ is as shown in (74).

$$
\begin{aligned}
& \llbracket \text { three books } \rrbracket=(73)[(64)] \\
& =\lambda B_{e \rightarrow T}\left\langle\exists x\left(|x| \geq 3 \wedge{ }^{*} \operatorname{book}^{\prime}(x) \wedge \pi_{1}(B(x)) \wedge \neg\left((\mathrm{PHYS} \sqcap \mathrm{INFO}) \sqcup \Omega_{1}(B)\right) \operatorname{comp}(x)\right),\right. \\
& \left.\quad \lambda h_{e \rightarrow \mathcal{R}} \cdot \exists v\left({ }^{*} \operatorname{book}^{\prime}(v) \wedge h(v) \sqsubseteq(\mathrm{PHYS} \sqcap \mathrm{INFO}) \wedge \pi_{2}(B(v))(h)\right)\right\rangle
\end{aligned}
$$

The lexical entry of the attributive adjective 'heavy' can also be adapted accordingly, as shown in (75).

$$
\begin{aligned}
& \llbracket \text { heavy } \_\rrbracket \\
& \begin{array}{l}
=\lambda Q_{e \rightarrow T} \cdot \lambda x_{e}\left\langle\left({ }^{*} \operatorname{heavy}^{\prime}(x) \wedge \pi_{1}(Q(x))\right),\right. \\
\qquad \\
\left.\quad \lambda g_{e \rightarrow R}\left(\exists h\left(\pi_{2}(Q(x))(h) \wedge g \sim_{x} h\right) \wedge g(x) \sqsubseteq\left(\operatorname{PHYS} \sqcup \Omega_{1}(Q)\right)\right)\right\rangle
\end{array}
\end{aligned}
$$


$g \sim_{x} h$ indicates that $g$ and $h$ differ at most with respect to $x$. We can now see how these lexical entries combine to give us an interpretation for 'three heavy books'.

$$
\begin{aligned}
& \llbracket \text { [heavy books } \rrbracket=(75)[(64)] \\
& =\lambda x_{e}\left\langle\left({ }^{*} \operatorname{heavy}^{\prime}(x) \wedge{ }^{*} \operatorname{book}^{\prime}(x)\right)\right. \text {, } \\
& \left.\lambda g_{e \rightarrow R}\left(\exists h\left(h(x) \sqsubseteq(\mathrm{PHYS} \sqcap \mathrm{INFO}) \wedge g \sim_{x} h\right) \wedge g(x) \sqsubseteq(\mathrm{PHYS} \sqcup(\mathrm{PHYS} \sqcap \mathrm{INFO}))\right)\right\rangle \\
& =\lambda x_{e}\left\langle\left({ }^{*} \operatorname{heavy}^{\prime}(x) \wedge{ }^{*} \operatorname{book}^{\prime}(x)\right)\right. \text {, } \\
& \left.\lambda g_{e \rightarrow R}\left(\exists h\left(h(x) \sqsubseteq(\mathrm{PHYS} \sqcap \mathrm{INFO}) \wedge g \sim_{x} h\right) \wedge g(x) \sqsubseteq \mathrm{PHYS}\right)\right\rangle
\end{aligned}
$$

The expression ' $\exists h\left(h(x) \sqsubseteq(\mathrm{PHYS} \sqcap \mathrm{INFO}) \wedge g \sim_{x} h\right)$ ' is redundant in the interpretation of

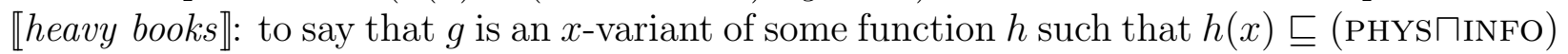
is to say that $g$ could in fact be anything. But if the expression were to contain more information about the function $h$ in addition to the value of $h(x)$, then the expression would not be redundant in that case. This would happen for example in the interpretation of 'heavy books that Steve likes', because in that case $h$ would contain information regarding the value of $h\left(s^{\prime}\right)$.

In any case, given the redundancy noted above, the interpretation of 'heavy books' is as shown in (76). Therefore, the interpretation of 'three heavy books' is as shown in (77).

$$
\begin{aligned}
& \llbracket \text { heavy books } \rrbracket=\lambda x_{e}\left\langle\left({ }^{*} \operatorname{heavy}^{\prime}(x) \wedge{ }^{*} \operatorname{book}^{\prime}(x)\right), \lambda g_{e \rightarrow R} . g(x) \sqsubseteq \mathrm{PHYS}\right\rangle \\
& \llbracket \text { three heavy books } \rrbracket=(73)[(76)] \\
& =\lambda B_{e \rightarrow T}\left\langle\exists x\left(|x| \geq 3 \wedge{ }^{*} \operatorname{heavy}^{\prime}(x) \wedge{ }^{*} \operatorname{book}^{\prime}(x) \wedge \pi_{1}(B(x)) \wedge \neg\left(\operatorname{PHYS} \sqcup \Omega_{1}(B)\right) \operatorname{comp}(x)\right)\right. \text {, } \\
& \left.\lambda h_{e \rightarrow \mathcal{R}} \cdot \exists v\left({ }^{*} \operatorname{heavy}^{\prime}(v) \wedge{ }^{*} \operatorname{book}^{\prime}(v) \wedge h(v) \sqsubseteq \operatorname{PHYS} \wedge \pi_{2}(B(v))(h)\right)\right\rangle
\end{aligned}
$$

It is worth comparing (74) to (77) to see how they make different contributions towards compressibility statements. The difference is analogous to that between (41) and (46) in Section 3.1.

With this much in place, we can see how these assumptions come together to derive the correct truth conditions for a copredication sentence (50) and a non-copredication sentence (49). For expository purposes, I will assume an approach to the syntax/semantics interface according to which the level of syntactic representation that is the input to interpretation (Logical Form) is the result of moving quantified DPs out of their surface positions. On this view, the semantically relevant structure of (50) would be something like that shown in (78). Here, the DP 'three heavy books' has moved from the object position, leaving a trace with index 1 , adjoined to its containing sentence (TP) and adjoined an index 1 to that sentence. 


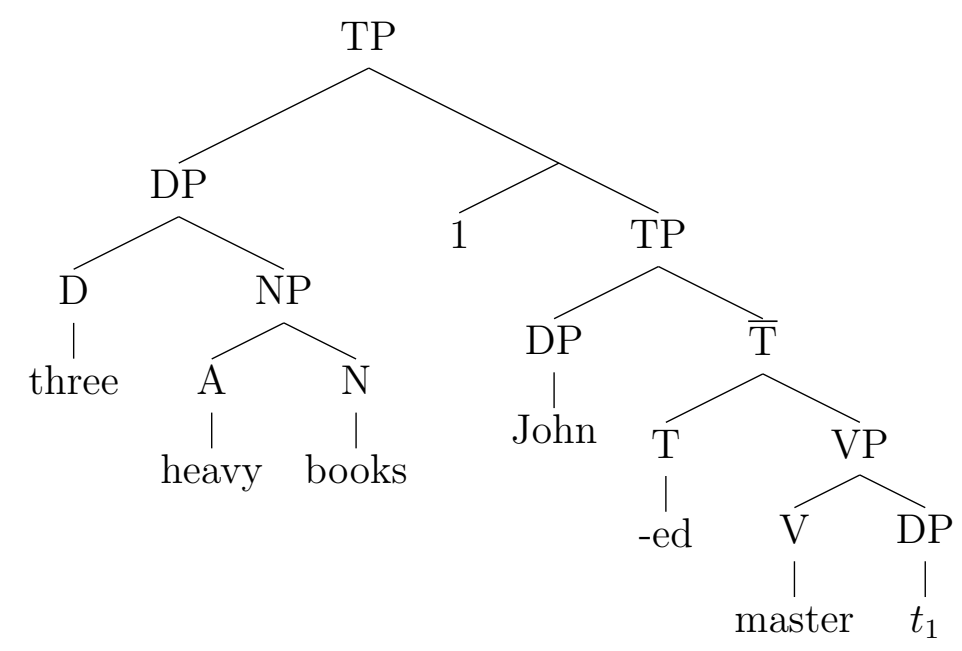

In this presentation I will ignore tense and treat the T node as semantically null.

The presence of movement in this system means that we need to relativize interpretation to an assignment function $\mathbf{g}$ - a function with domain the set of natural numbers and with range the domain of discourse $D_{e} \cdot{ }^{16}$ This can be done as shown in (79-a)-(79-b), requiring no addition to the system described by Heim and Kratzer (1998).

a. If $t_{i}$ is a trace, then $\llbracket t_{i} \rrbracket^{\mathrm{g}}=\mathbf{g}(i)$.

b. If $\alpha$ is a binary branching node with daughters $\beta$ and (numerical index) $i$, then $\llbracket \alpha \rrbracket^{\mathbf{g}}=\lambda v_{e} \cdot \llbracket \beta \rrbracket^{\mathbf{g}^{i / v}}$.

Where $\mathbf{g}^{i / v}$ is the function that is just like $\mathbf{g}$, except that $\mathbf{g}^{i / v}(i)=v$.

Based on (79-a) and the lexical entries stated above, we can see that the interpretation of the lower TP is as shown in (80).

$$
\llbracket T P \rrbracket^{\mathbf{g}}=\left\langle{ }^{*} \operatorname{master}^{\prime}\left(j^{\prime}, \mathbf{g}(1)\right), \lambda h_{e \rightarrow \mathcal{R}}\left(h\left(j^{\prime}\right) \sqsubseteq \mathrm{ANI} \wedge h(\mathbf{g}(1)) \sqsubseteq \mathrm{INFO}\right)\right\rangle
$$

Based on (79-b) and (80), we can see that the interpretation of its mother is as shown in (81).

$$
\lambda v_{e}\left\langle{ }^{*} \operatorname{master}^{\prime}\left(j^{\prime}, v\right), \lambda h_{e \rightarrow \mathcal{R}}\left(h\left(j^{\prime}\right) \sqsubseteq \mathrm{ANI} \wedge h(v) \sqsubseteq \mathrm{INFO}\right)\right\rangle
$$

Given that the semantic value of the moved DP 'three heavy books' is the same as shown in (77), the interpretation of the whole sentence is as shown in (82). ${ }^{17}$

$$
\begin{aligned}
& \llbracket J o h n \text { mastered three heavy books } \rrbracket=(77)[(81)] \\
& =\left\langle\exists x\left(|x| \geq 3 \wedge{ }^{*} \operatorname{heavy}^{\prime}(x) \wedge{ }^{*} \operatorname{book}^{\prime}(x) \wedge{ }^{*} \operatorname{master}^{\prime}\left(j^{\prime}, x\right) \wedge \neg(\text { PHYS } \sqcup \mathrm{INFO}) \operatorname{comp}(x)\right),\right. \\
& \left.\lambda h_{e \rightarrow \mathcal{R}} \cdot \exists v\left({ }^{*} \operatorname{heavy}^{\prime}(v) \wedge{ }^{*} \operatorname{book}^{\prime}(v) \wedge h(v) \sqsubseteq \text { PHYS } \wedge h\left(j^{\prime}\right) \sqsubseteq \text { ANI } \wedge h(v) \sqsubseteq \mathrm{INFO}\right)\right\rangle \\
& =\left\langle\exists x\left(|x| \geq 3 \wedge{ }^{*} \operatorname{heavy}^{\prime}(x) \wedge{ }^{*} \operatorname{book}^{\prime}(x) \wedge{ }^{*} \operatorname{master}^{\prime}\left(j^{\prime}, x\right) \wedge \neg(\text { PHYS } \sqcup \mathrm{INFO}) \operatorname{comp}(x)\right),\right. \\
& \left.\lambda h_{e \rightarrow \mathcal{R}} \cdot \exists v\left(* \operatorname{heavy}^{\prime}(v) \wedge{ }^{*} \operatorname{book}^{\prime}(v) \wedge h(v) \sqsubseteq(\mathrm{PHYS} \sqcap \mathrm{INFO}) \wedge h\left(j^{\prime}\right) \sqsubseteq \mathrm{ANI}\right)\right\rangle
\end{aligned}
$$

\footnotetext{
${ }^{16}$ For ease of presentation I am assuming that traces can only be of type $e$.

${ }^{17} \mathrm{I}$ omit reference to the assignment function when it is not relevant.
} 
In the last line of working the inference has been made from $h(v) \sqsubseteq \operatorname{PHYS} \wedge h(v) \sqsubseteq$ INFO to $h(v) \sqsubseteq$ (PHYS $\sqcap$ INFO), which is licensed by (53-c).

The first projection of (82) - the extensional meaning of the sentence - is identical to (58), as desired. It says that there are three books that are heavy and that John mastered, none of which is physically or informationally equivalent to any other.

In the non-copredication case, the interpretation of the whole sentence is as shown in $(83)$.

$$
\begin{aligned}
& \llbracket \text { John mastered three books } \rrbracket=(74)[(81)] \\
& =\left\langle\exists x\left(|x| \geq 3 \wedge{ }^{*} \operatorname{book}^{\prime}(x) \wedge * \text { master }\left(j^{\prime}, x\right) \wedge \neg(\mathrm{INFO}) \operatorname{comp}(x)\right),\right. \\
& \left.\quad \lambda h_{e \rightarrow \mathcal{R}} \cdot \exists v\left({ }^{*} \operatorname{book}^{\prime}(v) \wedge h(v) \sqsubseteq(\mathrm{PHYS} \sqcap \mathrm{INFO}) \wedge h\left(j^{\prime}\right) \sqsubseteq \mathrm{ANI}\right)\right\rangle
\end{aligned}
$$

The first projection of (83) - the extensional meaning of the sentence - is identical to (57), as desired. It says that there are three books that John mastered, none of which is informationally equivalent to any other - not ruling out the possibility that one may be physically equivalent to another. So we can see that the compositionally-derived compressibility statements deliver the correct truth conditions in these cases.

\subsection{Extensions}

The lexical entries given in Section 3.2, together with standard compositional principles, derive adequate interpretations for copredication and non-copredication sentences of the form shown in (4)-(6). In this section I will describe how the system developed so far can be extended to some other constructions in which individuation and/or copredication is an issue.

\subsubsection{Coordination}

Often copredication arises in a coordinate structure. For example, just like (6) and (50), both (84) and (85) require that the books in question all be both physically and informationally distinct from each other.

(84) Three books are heavy and informative.

(85) John picked up and mastered three books.

In order to ensure that these distinctness requirements are imposed, we have to provide lexical entries for intransitive and transitive verb conjunctions that combine the constructions of each verb in the right way. For (84) we have the intransitive verb conjunction shown in (86).

$$
\begin{aligned}
\lambda A_{e \rightarrow T} \cdot \lambda B_{e \rightarrow T} \cdot \lambda x_{e}\langle & \left(\pi_{1}(A(x)) \wedge \pi_{1}(B(x))\right) \\
\lambda f_{e \rightarrow R}\left(\exists g\left(\pi_{2}(A(x))(g) \wedge f \sim_{x} g\right)\right. & \\
& \left.\left.\wedge \exists h\left(\pi_{2}(B(x))(h) \wedge f \sim_{x} h\right) \wedge f(x) \sqsubseteq\left(\Omega_{1}(A) \sqcup \Omega_{1}(B)\right)\right)\right\rangle
\end{aligned}
$$




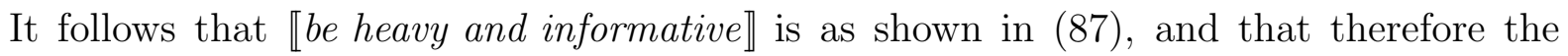
interpretation of (84) is as shown in (88).

$$
\begin{aligned}
& \llbracket \text { be heavy and informative } \rrbracket=(86)[(66)][(65)] \\
& =\lambda x_{e}\left\langle\left({ }^{*} \operatorname{heavy}^{\prime}(x) \wedge *^{*} \operatorname{inform}^{\prime}(x)\right)\right. \text {, } \\
& \lambda f_{e \rightarrow R}\left(\exists g\left(g(x) \sqsubseteq \text { PHYS } \wedge f \sim_{x} g\right)\right. \\
& \left.\left.\wedge \exists h\left(h(x) \sqsubseteq \operatorname{INFO} \wedge f \sim_{x} h\right) \wedge f(x) \sqsubseteq(\mathrm{PHYS} \sqcup \mathrm{INFO})\right)\right\rangle \\
& =\lambda x_{e}\left\langle\left({ }^{*} \operatorname{heavy}^{\prime}(x) \wedge *^{*} \text { inform }^{\prime}(x)\right), \lambda f_{e \rightarrow R} \cdot f(x) \sqsubseteq(\text { PHYS } \sqcup \text { INFO })\right\rangle
\end{aligned}
$$

$$
\begin{aligned}
& \llbracket \text { Three books are heavy and informative } \rrbracket=(74)[(87)] \\
& =\left\langle\exists x\left(|x| \geq 3 \wedge{ }^{*} \operatorname{book}^{\prime}(x) \wedge{ }^{*} \operatorname{heavy}^{\prime}(x) \wedge * \operatorname{inform}^{\prime}(x) \wedge \neg(\text { PHYS } \sqcup \operatorname{INFO}) \operatorname{comp}(x)\right),\right. \\
& \left.\quad \lambda f_{e \rightarrow R} \cdot \exists v\left({ }^{*} \operatorname{book}^{\prime}(v) \wedge f(v) \sqsubseteq(\text { PHYS } \sqcup \operatorname{INFO})\right)\right\rangle
\end{aligned}
$$

The first projection of (88) is identical to that of (47), which is as desired as the two sentences have the same truth conditions. It says that there is a plurality of three heavy and informative books, which is neither physically nor informationally compressible.

For (85) we have the transitive verb conjunction shown in (89).

$$
\begin{aligned}
& \lambda A_{e \rightarrow(e \rightarrow T)} \cdot \lambda B_{e \rightarrow(e \rightarrow T)} \cdot \lambda x_{e} \cdot \lambda y_{e} \\
& \left\langle\pi_{1}(A(x)(y)) \wedge \pi_{1}(B(x)(y)),\right. \\
& \lambda g_{e \rightarrow \mathcal{R}} \cdot \exists h\left(\pi_{2}(A(x)(y))(h) \wedge h \sim_{x, y} g\right) \wedge g(x) \sqsubseteq\left(\Omega_{2}(A) \sqcup \Omega_{2}(B)\right) \\
& \left.\wedge \exists f\left(\pi_{2}(B(x)(y))(f) \wedge f \sim_{x, y} g\right) \wedge g(y) \sqsubseteq\left(\Omega_{1}(A(x)) \sqcup \Omega_{1}(B(x))\right)\right\rangle
\end{aligned}
$$

If we have the lexical entry for 'master' shown in (55), it follows that $\llbracket p i c k e d$ up and mastered $\rrbracket$ is as shown in (91).

$$
\begin{aligned}
& \llbracket \text { master }_{p l} \rrbracket=\lambda x_{e} \cdot \lambda y_{e}\left\langle{ }^{*} \operatorname{master}^{\prime}(y, x), \lambda f_{e \rightarrow \mathcal{R}}(f(y) \sqsubseteq \mathrm{ANI} \wedge f(x) \sqsubseteq \mathrm{INFO})\right\rangle \\
& \llbracket \text { picked up and mastered } \rrbracket=(89)[(90)][(61)[(55)]] \\
& =\lambda x_{e} \cdot \lambda y_{e}\left\langle\left({ }^{*} \operatorname{pick}^{\prime} \operatorname{up}^{\prime}(y, x) \wedge{ }^{*} \operatorname{master}^{\prime}(y, x)\right)\right. \text {, } \\
& \lambda g_{e \rightarrow \mathcal{R}} \cdot \exists h\left(h(x) \sqsubseteq \mathrm{PHYS} \wedge h(y) \sqsubseteq \mathrm{ANI} \wedge h \sim_{x, y} g\right) \wedge g(x) \sqsubseteq(\mathrm{PHYS} \sqcup \mathrm{INFO}) \\
& \left.\wedge \exists f\left(f(x) \sqsubseteq \mathrm{INFO} \wedge f(y) \sqsubseteq \mathrm{ANI} \wedge f \sim_{x, y} g\right) \wedge g(y) \sqsubseteq(\mathrm{ANI} \sqcup \mathrm{ANI})\right\rangle \\
& =\lambda x_{e} \cdot \lambda y_{e}\left\langle\left({ }^{*} \operatorname{pick}^{\prime} \operatorname{up}^{\prime}(y, x) \wedge{ }^{*} \operatorname{master}^{\prime}(y, x)\right)\right. \text {, } \\
& \left.\lambda g_{e \rightarrow \mathcal{R}} \cdot g(x) \sqsubseteq(\mathrm{PHYS} \sqcup \mathrm{INFO}) \wedge g(y) \sqsubseteq(\mathrm{ANI} \sqcup \mathrm{ANI})\right\rangle \\
& =\lambda x_{e} \cdot \lambda y_{e}\left\langle\left({ }^{*} \operatorname{pick}^{-u_{p}}(y, x) \wedge{ }^{*} \operatorname{master}^{\prime}(y, x)\right)\right. \text {, } \\
& \left.\lambda g_{e \rightarrow \mathcal{R}} \cdot g(x) \sqsubseteq(\mathrm{PHYS} \sqcup \mathrm{INFO}) \wedge g(y) \sqsubseteq \mathrm{ANI}\right\rangle
\end{aligned}
$$

Adopting the assumptions of the previous section, the structure of (85) that is the input to interpretation would be something like that shown in (92). 


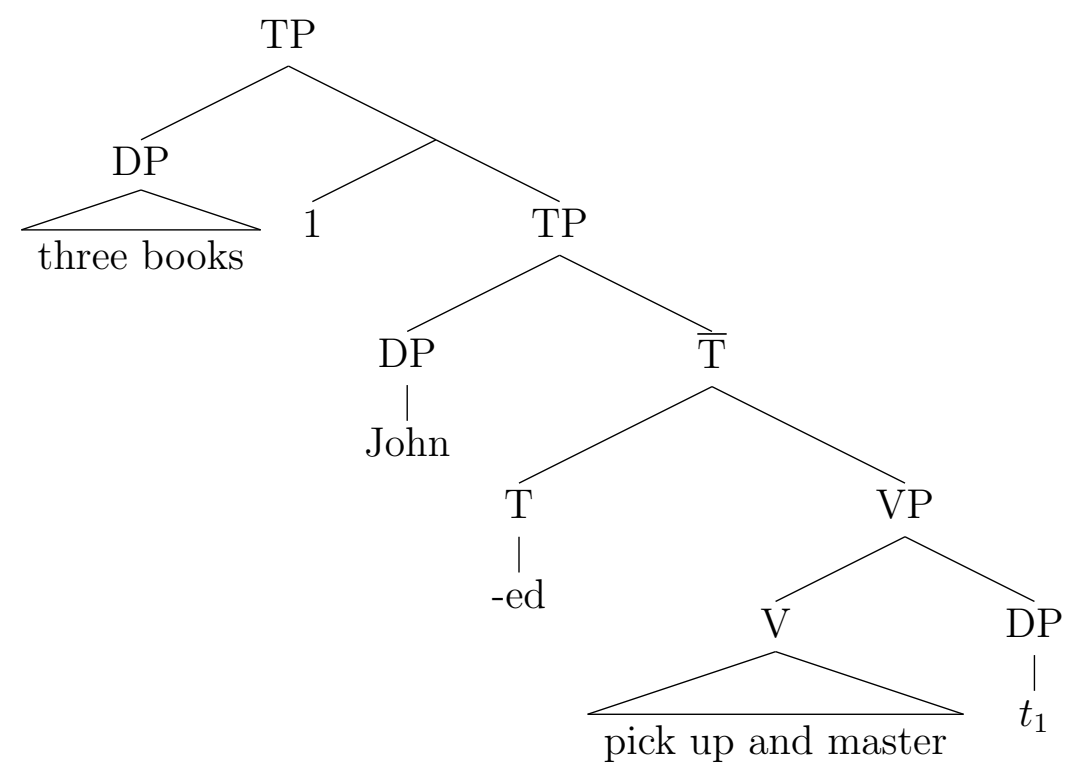

The interpretation of the lower TP in (92) is as shown in (93).

$$
\begin{aligned}
\llbracket T P \rrbracket^{\mathbf{g}}= & (91)[\mathbf{g}(1)]\left[j^{\prime}\right] \\
= & \left\langle\left({ }^{*} \operatorname{pick}^{\prime} \operatorname{up}^{\prime}\left(j^{\prime}, \mathbf{g}(1)\right) \wedge{ }^{*} \operatorname{master}^{\prime}\left(j^{\prime}, \mathbf{g}(1)\right)\right),\right. \\
& \left.\lambda f_{e \rightarrow \mathcal{R}}\left(f(\mathbf{g}(1)) \sqsubseteq(\mathrm{PHYS} \sqcup \mathrm{INFO}) \wedge f\left(j^{\prime}\right) \sqsubseteq \mathrm{ANI}\right)\right\rangle
\end{aligned}
$$

The interpretation of its mother is therefore as shown in (94).

$$
\lambda v_{e}\left\langle\left({ }^{*} \operatorname{pick}_{-u^{\prime}}\left(j^{\prime}, v\right) \wedge{ }^{*} \operatorname{master}^{\prime}\left(j^{\prime}, v\right)\right), \lambda f_{e \rightarrow \mathcal{R}}\left(f(v) \sqsubseteq(\mathrm{PHYS} \sqcup \mathrm{INFO}) \wedge f\left(j^{\prime}\right) \sqsubseteq \mathrm{ANI}\right)\right\rangle
$$

And this in turn means that the interpretation of (85) is as shown in (95).

$$
\begin{aligned}
& \llbracket J o h n \text { picked up and mastered three books }=(74)[(94)] \\
& =\left\langle\exists x\left(|x| \geq 3 \wedge{ }^{*} \operatorname{book}^{\prime}(x) \wedge{ }^{*} \operatorname{pick} \text { up }^{\prime}\left(j^{\prime}, x\right) \wedge{ }^{*} \operatorname{master}^{\prime}\left(j^{\prime}, x\right) \wedge \neg(\mathrm{PHYS} \sqcup \operatorname{INFO}) \operatorname{comp}(x)\right),\right. \\
& \left.\lambda h_{e \rightarrow \mathcal{R}} \cdot \exists v\left({ }^{*} \operatorname{book}^{\prime}(v) \wedge h(v) \sqsubseteq(\mathrm{PHYS} \sqcap \mathrm{INFO}) \wedge h(v) \sqsubseteq(\mathrm{PHYS} \sqcup \mathrm{INFO}) \wedge h\left(j^{\prime}\right) \sqsubseteq \mathrm{ANI}\right)\right\rangle \\
& =\left\langle\exists x\left(|x| \geq 3 \wedge{ }^{*} \operatorname{book}^{\prime}(x) \wedge{ }^{*} \operatorname{pick}^{\prime} \operatorname{up}^{\prime}\left(j^{\prime}, x\right) \wedge{ }^{*} \operatorname{master}^{\prime}\left(j^{\prime}, x\right) \wedge \neg(\text { PHYS } \sqcup \operatorname{INFO}) \operatorname{comp}(x)\right),\right. \\
& \left.\lambda h_{e \rightarrow \mathcal{R}} \cdot \exists v\left({ }^{*} \operatorname{book}^{\prime}(v) \wedge h(v) \sqsubseteq(\mathrm{PHYS} \sqcap \mathrm{INFO}) \wedge h\left(j^{\prime}\right) \sqsubseteq \mathrm{ANI}\right)\right\rangle
\end{aligned}
$$

The first projection of (95) gives correct truth conditions for (85): it says that John picked up and mastered three books, all of which are physically and informationally distinct from each other. For any conjoinable category a conjunction like (89) can be stated that preserves the individuation relations present in its arguments in the right way. So criteria of individuation for copredication arising in coordinate structures can be accounted for in essentially the same way as for copredication arising in other structures.

\subsubsection{A note on singular nouns}

So far we have only been considering plural quantifiers. Do issues of individuation arise with singular quantifiers as well? Consider (96) and (97). 
John picked up every book.

(97) John mastered every book.

Suppose that there are three copies of The Language Instinct, and no other books, in a situation $s_{1}$. That is to say, the books in $s_{1}$ are the members of the set shown in (98).

$$
\left\{v_{1}+T L I, v_{2}+T L I, v_{3}+T L I\right\}
$$

For (97) to be true, it must only be the case that John mastered one informational book (The Language Instinct), whereas for (96) to be true, it must be the case that John picked up three physical books (all three copies).

Given the assumptions made so far, this does not actually necessitate a special treatment of 'every'. For instance, suppose we use the lexical entry for 'every' shown in (99), such that no construction-based information is incorporated into truth conditions.

$$
\begin{aligned}
\llbracket \text { every } \rrbracket \lambda P_{e \rightarrow T} \cdot \lambda Q_{e \rightarrow T}\langle & \forall x\left(\pi_{1}(P(x)) \rightarrow \pi_{1}(Q(x))\right), \\
& \left.\lambda f_{e \rightarrow \mathcal{R}} \cdot \exists v\left(\pi_{1}(A(v)) \wedge \pi_{2}(A(v))(f) \wedge \pi_{2}(B(v))(f)\right)\right\rangle
\end{aligned}
$$

(99) has no compressibility statement, but it does not matter. If John mastered The Language Instinct, then, given the assumptions we have been making (see the beginning of Section 2), he mastered $v_{1}+T L I, v_{2}+T L I$ and $v_{3}+T L I$, and so (97) is true in $s_{1}$. But if he picked up $v_{1}$ and not $v_{2}$ or $v_{3}$, then (96) is false in $s_{1}$, because (on the same assumptions) he picked up $v_{1}+T L I$ but not $v_{2}+T L I$ or $v_{3}+T L I$.

Of course, it does not follow from any of this that 'John mastered three books' is true in $s_{1} \cdot v_{1}+T L I, v_{2}+T L I$ and $v_{3}+T L I$ may be distinct books, but they are informationally equivalent, which is the relevant consideration for the truth conditions of 'John mastered three books'. It is a welcome feature of this treatment that it captures the invalidity of the argument shown in (100).

John picked up three books.

John mastered every book.

John mastered three books.

The reason for this is that, although the argument form shown in (101) is valid, (100) actually follows the argument form shown in (102), which is invalid.

$$
\begin{aligned}
& \exists x\left(|x| \geq 3 \wedge{ }^{*} \operatorname{book}^{\prime}(x) \wedge \wedge^{*} \operatorname{pick}^{\prime} \operatorname{up}^{\prime}\left(j^{\prime}, x\right)\right) \\
& \forall x\left(\operatorname{book}^{\prime}(x) \rightarrow \operatorname{master}^{\prime}\left(j^{\prime}, x\right)\right) \\
& \exists x\left(|x| \geq 3 \wedge^{*} \operatorname{book}^{\prime}(x) \wedge^{*} \text { master }\left(j^{\prime}, x\right)\right) \\
& \exists x\left(|x| \geq 3 \wedge{ }^{*} \operatorname{book}^{\prime}(x) \wedge \neg(\operatorname{PHYS}) \operatorname{comp}(x) \wedge{ }^{*} \operatorname{pick-up}^{\prime}\left(j^{\prime}, x\right)\right) \\
& \forall x\left(\operatorname{book}^{\prime}(x) \rightarrow \operatorname{master}^{\prime}\left(j^{\prime}, x\right)\right) \\
& \exists x\left(|x| \geq 3 \wedge^{*} \operatorname{book}^{\prime}(x) \wedge \neg(\operatorname{INFO}) \operatorname{comp}(x) \wedge^{*} \operatorname{master}^{\prime}\left(j^{\prime}, x\right)\right)
\end{aligned}
$$

By the same logic, the argument shown in (103) is valid, as it has the form shown in (104). This is another welcome result of the current system. ${ }^{18}$

\footnotetext{
${ }^{18} \mathrm{I}$ am assuming that 'defaced' also asserts physical individuation in its object position.
} 
John picked up three books.

John defaced every book.

John defaced three books.

$$
\begin{aligned}
& \exists x\left(|x| \geq 3 \wedge{ }^{*} \operatorname{book}^{\prime}(x) \wedge \neg(\text { PHYS }) \operatorname{comp}(x) \wedge * \operatorname{pick}^{\prime} \operatorname{up}^{\prime}\left(j^{\prime}, x\right)\right) \\
& \forall x\left(\operatorname{book}^{\prime}(x) \rightarrow \operatorname{deface}^{\prime}\left(j^{\prime}, x\right)\right) \\
& \exists x\left(|x| \geq 3 \wedge \operatorname{book}^{\prime}(x) \wedge \neg(\text { PHYS }) \operatorname{comp}(x) \wedge * \operatorname{deface}^{\prime}\left(j^{\prime}, x\right)\right)
\end{aligned}
$$

No wrong predictions emerge from simply taking the domain of quantification to include

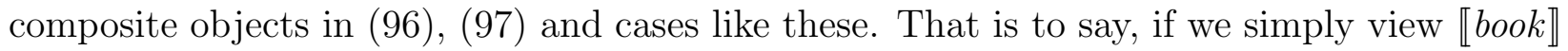
as the set of composite objects made up of a part that is a physical book and a part that is an informational book that it instantiates, then no individuation conundrums emerge as they do for sentences involving numerical quantification.

There is a possible exception, however, concerning ambiguities that arise with the verb 'read' in sentences like (105).

(105) John read every book.

On one reading, (105) is true if John read at least one copy of every book. On the other reading, (105) can only be true if he read every copy of every book, which normally would require reading some informational books several times. Suppose that we have the same situation $s_{1}$ outlined above, in which the only books are the three copies of The Language Instinct mentioned above. If John took out one copy ( $v_{1}$, say) and read it, but never touched the others, then there is a reading of (105) on which it is true, and also a reading on which it is false.

I propose to treat this this issue by attributing ambiguity to the word 'read', rather than locating the necessary flexibility in the treatment of quantification as such. The approach to the ambiguity of (105) proceeds as follows. There is a meaning of 'read' that is like this: modulo construction, it is a relation between individuals and informational objects. Let's call this ' $\operatorname{read}_{1}$ '. On this view, if John has read The Language Instinct, then TLI is in $\llbracket \lambda_{1}\left[J_{\text {ohn }}\right.$ read $\left._{1} t_{1}\right] \rrbracket$, and therefore so are the composite objects of which TLI is a part ${ }^{19}$ _so in the domain in question, $v_{1}+T L I, v_{2}+T L I$ and $v_{3}+T L I$. We would therefore have (106).

$$
\llbracket \lambda_{1}\left[\text { John read }_{1} t_{1}\right] \rrbracket^{s_{1}}=\left\{\mathrm{TLI}, v_{1}+T L I, v_{2}+T L I, v_{3}+T L I\right\}
$$

It follows that $(105)$ is true in the situation being described, because $(98) \subseteq(106)$.

To get the reading of (105) on which it is not true in the situation being described, we must posit the existence of a second verb, ' $\operatorname{read}_{2}$ ', which takes composite physical+informational objects in its extension directly, i.e. not via inheritance from their informational parts in the sense outlined above. On this view, $\llbracket r e a d_{2} \rrbracket$ is (modulo construction) a relation between individuals and physical+informational composite objects. Therefore, in $s_{2}$ the only object that John $\operatorname{read}_{2}$ is $v_{1}+T L I$. TLI by itself is not in $\llbracket \lambda_{1}\left[J_{\text {ohn }}\right.$ read $\left._{2} t_{1}\right] \rrbracket$ no simple object is - and $v_{2}+T L I$ and $v_{3}+T L I$ are not in $\llbracket \lambda_{1}\left[J\right.$ ohn read $\left.t_{1}\right] \rrbracket$, because when John read The Language Instinct it did not involve $v_{2}$ or $v_{3}$. We would therefore have (107). Because $(98) \nsubseteq(107)$, on this reading (105) is not true in situation $s_{1}$.

(107) $\llbracket \lambda_{1}\left[\right.$ John read $\left.t_{1}\right] \rrbracket^{s_{1}}=\left\{v_{1}+T L I\right\}$

\footnotetext{
${ }^{19}$ See the beginning of $\S 2$
} 

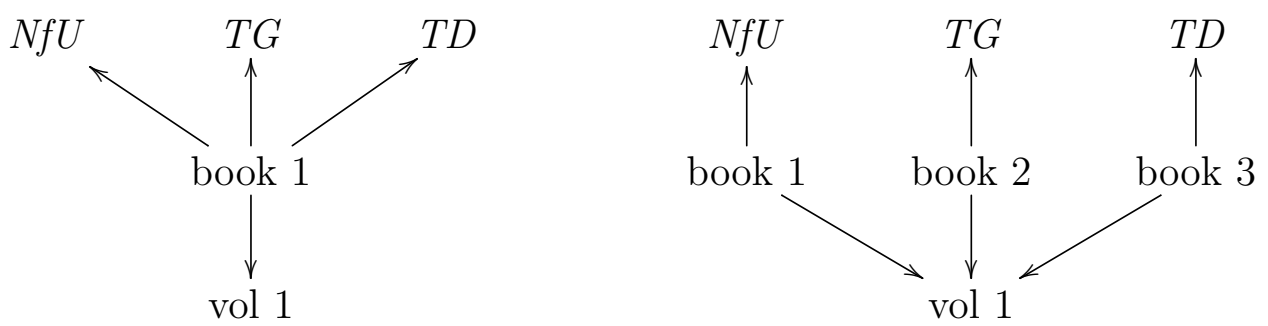

Figure 3: A trilogy, under physical and informational criteria of individuation respectively

In summary, unlike plural determiners, there is no need for a singular determiner like 'every' to manipulate individuation relations in order to derive the different interpretations of (105), provided that we countenance lexical ambiguity of 'read'.

\section{Comparison with other approaches}

In this section the formal approach to copredication presented in Section 3 will be compared with other prominent approaches in the literature, focusing primarily on issues of quantification and individuation.

\subsection{Asher's Type Composition Logic}

According to the theory described by Asher (2011), nouns supporting copredication do not denote composite objects, but rather 'dot objects' (Pustejovsky, 1995) - that is, objects that can be conceptualised in different ways or, in his terminology, viewed under different 'aspects'. Asher describes his view of 'aspects' as follows:

Given the way I have defined aspects, the sum of an object's aspects cannot be identical to the object itself (since each aspect contains the object together with some property that it has). A lunch object is wholly an event (under one aspect) and wholly food (under another aspect). (Asher, 2011, 149-150)

To get a handle on this way of thinking, let's imagine a situation in which we have three (informational) books printed in a single (physical) volume. Concretely, let's imagine that we have a volume containing the Dostoyevsky novellas Notes from Underground, The Gambler and The Double. In Asher's view, this situation can be conceptualised in two different ways, as indicated in Figure 3. The informational objects are listed as ' $N f U$ ', ' $T G$ ' and ' $T D$ ' and the single physical volume is 'vol 1'.

Conceptualised in one way, shown on the left hand side of the figure, there is one book. Conceptualised in another way, shown on the right hand side of the figure, there are three books. In both cases $a \longrightarrow b$ is supposed to indicate that $b$ is an aspect of $a$. In Asher's metalanguage formulae, this is represented as 'o-elab' $(b, a)$ ' $-b$ is an 'object elaboration' of $a$.

Although the number of aspects of each type is the same under the two conceptualisations, then, the number of books is different. That means that changing conceptualisation can change the domain of quantification: 
The bare objects of $\bullet$ type [e.g. books] are counted and individuated relative to one of their constituent types [...] We should relativize the domain of quantification in a world to a criterion of individuation (Asher, 2011, 157-159)

For the situation described, then, there are two possible criteria of individuation ${ }^{20}$ to which the domain of quantification can be relativised: physical and informational. The model for these cases is partially described in (108) and (109) respectively.

$$
\begin{aligned}
& \text { Domain }(\text { Fig. 3) })^{\text {Physical }}=\{\text { vol 1, NfU, TG, TD, book } 1\} \\
& \llbracket \text { o-elab } \rrbracket^{\text {Physical }}=\{\langle\text { vol 1, book } 1\rangle,\langle N f U, \text { book } 1\rangle,\langle T G, \text { book } 1\rangle,\langle T D, \text { book } 1\rangle\} \\
& \llbracket \text { book }^{\prime} \rrbracket^{\text {Physical }}=\{\text { book } 1\}
\end{aligned}
$$

(109) Domain(Fig. 3) $)^{\text {Informational }}=\{\operatorname{vol} 1, N f U, T G, T D$, book 1, book 2, book 3$\}$

$\llbracket$ o-elab $\rrbracket^{\text {Informational }}=\{\langle\operatorname{vol} 1$, book 1$\rangle,\langle\operatorname{vol} 1$, book 2$\rangle,\langle$ vol 1, book 3$\rangle$,

$$
\langle N f U \text {, book } 1\rangle,\langle T G \text {, book } 2\rangle,\langle T D \text {, book } 3\rangle\}
$$

$\llbracket$ book $^{\prime} \rrbracket^{\text {Informational }}=\{$ book 1 , book 2 , book 3$\}$

One might wonder what the difference is between book 1 and vol 1 in (108), or between e.g. book 2 and The Gambler in (109). Relative to a physical criterion of individuation (as in (108) or on the left hand side of Figure 3 ) there is a one-to-one correspondence between books and physical aspects of books, and relative to an informational criterion of individuation (as in (109) or on the right hand side of Figure 3) there is a one-to-one correspondence between books and informational aspects of books. However, these are distinct objects: one is a 'bare particular' while the other is a 'thick individual' (Asher, 2011, 149).

In most cases the truth conditions predicted in Asher's system will involve quantification over aspects rather than over books as such, so that the way a particular situation is conceptualised will not make a truth-conditional difference. However, there are exceptions to this, which will be discussed below.

The compositional system, called 'Type Composition Logic' or TCL, is built on a framework that involves subtypes of $e$ (the type of entities), for instance $\mathrm{P}$ the type of physical objects and I the type of informational objects. Dot objects are of a special dot type, for

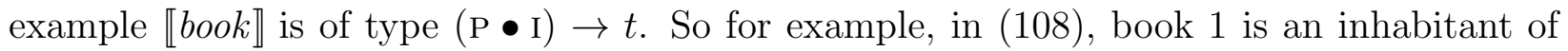
type P•I, vol 1 is an inhabitant of type P, and Notes from Underground, The Gambler and The Double are inhabitants of type I.

Dot types $\alpha \bullet \beta$ do not, in general, stand in a subtyping relationship to their constituent types $\alpha$ and $\beta$ and therefore cannot be used directly in a context requiring either of those constituent types; however, there are particular compositional accommodation rules that apply so that they can be used in those contexts. In non-copredication sentences, quantification is over aspects of the appropriate type, e.g. over physical objects or informational objects as appropriate. For instance, the truth conditions predicted for (48) are as shown in (110).

$$
\begin{aligned}
& \lambda \pi . \exists v\left(v=j^{\prime}(\pi) \wedge \exists_{3} x\left(\operatorname{pick}_{-u^{\prime}}(v, x, \pi) \wedge \exists z\left(\operatorname{book}^{\prime}(z, \pi) \wedge \mathrm{o}-\operatorname{elab}(x, z, \pi)\right)\right)\right) \\
& \pi: \quad v: \mathrm{A}, x: \mathrm{P}, z: \mathrm{P} \bullet \mathrm{I}
\end{aligned}
$$

\footnotetext{
${ }^{20}$ See footnote 6 on p. 6 .
} 

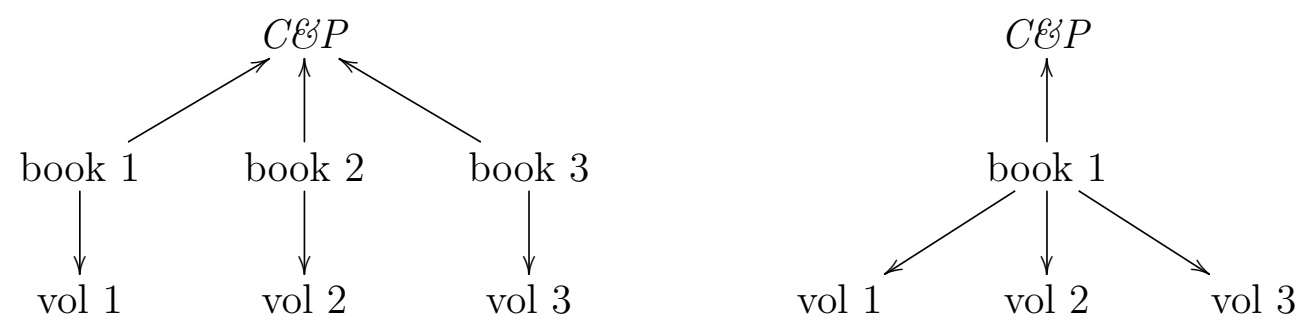

Figure 4: Three copies of one informational book, under physical and informational criteria of individuation respectively

In Asher's theory, $\pi$ is a presupposition parameter that assigns types to argument positions of predicates. ${ }^{21}$ What (110) says is that there are three objects ${ }^{22}$ of type P (physical), each of which is an aspect of a book and each of which John picked up. (110) is therefore not true in the situation shown in Figure 3: under neither conceptualisation are there three physical aspects - indeed, changing conceptualisation never changes the number of aspects. The only inhabitant of type $\mathrm{P}$ in (108) or (109) is vol 1.

However, (110) is true in the situation shown in Figure 4, where we have three (physical) copies of the same (informational) book (in this case, Crime and Punishment), provided that John picked up those volumes. Here, under either conceptualisation there are three physical aspects, as can be seen from the partial model descriptions in (111) and (112).

(111) Domain(Fig. 4) $)^{\text {Physical }}=\{\operatorname{vol} 1$, vol 2, vol 3, CESP, book 1, book 2, book 3$\}$

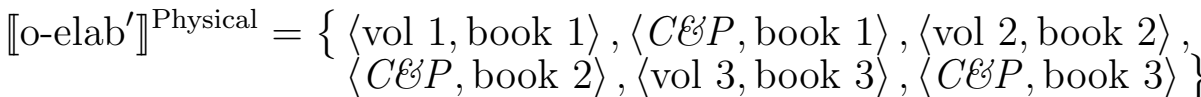

$\llbracket$ book $^{\prime} \rrbracket^{\text {Physical }}=\{$ book 1, book 2, book 3$\}$

(112) Domain(Fig. 4) $)^{\text {Informational }}=\{$ vol 1, vol 2, vol 3, book 1, C\&̈P $\}$

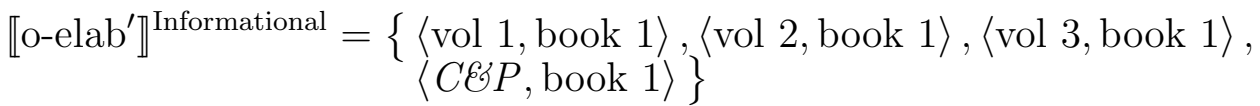

$\llbracket$ book $^{\prime} \rrbracket^{\text {Informational }}=\{$ book 1$\}$

In both (111) and (112), vol 1, vol 2 and vol 3 are inhabitants of type P and are aspects of some book. So (110) is true in this situation, irrespective of conceptualisation.

These are welcome results, as we would want to say that (48) is unequivocally true in the situation shown in Figure 4 and unequivocally false in the situation shown in Figure 3. However, in some cases the results are not so welcome, as we will now see.

The type assignments for (110) stored in the $\pi$ parameter, which above I summarised as shown (repeated) in (113), are actually of the form shown in (114).

$$
\begin{aligned}
& v: \mathrm{A}, x: \mathrm{P}, z: \mathrm{P} \bullet \mathrm{I} \\
& * \arg _{1}^{\text {pick-up }^{\prime}}: \mathrm{A} * \arg _{2}^{\text {pick-up' }}: \mathrm{P} * \arg _{1}^{\text {book }^{\prime}}: \mathrm{P} \bullet \mathrm{I} * \arg _{1}^{\text {o-elab }}: \mathrm{P} * \arg _{1}^{\text {o-elab }}: \mathrm{P} \bullet \mathrm{I}
\end{aligned}
$$

(114) states that:

\footnotetext{
${ }^{21}$ It is not the projection function that I made use of in Section 3.

${ }^{22}$ That's the significance of Asher's quantifier ' $\exists_{3}$ '.
} 
- The first argument position of pick-up' is of type A (for 'animate')

- The second argument position of pick-up' is of type P

- The first argument position of book' is of type P $\bullet$ I

- The first argument position of o-elab' is of type $\mathrm{P}$

- The second argument position of o-elab' is of type P $\bullet$ I

So, for example, $\operatorname{book}^{\prime}(x, \pi)$ means that $x$ is a book, and the sequence of type assignments stored in $\pi$ is coherent. In this case, the sequence of type assignments listed in (114) is coherent when applied to (110).

In some circumstances where the sequence of type assignments stored in $\pi$ is not coherent, special accommodation rules apply. This is what happens when $\alpha \bullet \beta$ is expected and $\alpha$ is provided (or vice versa). The way these rules work is by introducing extra 'o-elab' arguments into metalanguage interpretations - so (110) shows an interpretation derived in part by the application of these accommodation rules.

In these cases, there remains the question of which typing expectation $-\alpha \bullet \beta$ or $\alpha$ - to accommodate to which, as both kinds of shift are possible within Asher's system. The system is set up so that by default, if $\alpha \bullet \beta$ was introduced by an expression of syntactic category $\mathrm{X}$ and $\alpha$ was introduced by an expression of category $\mathrm{Y}$, then $\alpha \bullet \beta$ is accommodated to $\alpha$ if $\mathrm{Y}$ projects and $\alpha$ is accommodated to $\alpha \bullet \beta$ if X projects. ${ }^{23}$ For instance, what has happened in the derivation of (110) is that the accommodation functor shown in 115 has applied to convert (116) (which is derived by abstraction from a part of the metalanguage formula introduced by 'three books') to (117).

(116) $\lambda y \cdot \lambda \pi_{2} \cdot \operatorname{book}^{\prime}\left(y, \pi_{2}\right)$

(117) $\lambda u \cdot \lambda \pi \cdot \exists z\left(\operatorname{book}^{\prime}(z, \pi) \wedge\right.$ o-elab $\left.(u, z, \pi)\right)$

This means that what was the 'book' property, (116), is now the 'book conceptualised as physical object' property, (117). We have moved from the middle line of Figure 4 to the bottom line. The result is that in (110) the numerical quantifer (Asher's ' $\exists_{3}$ ') binds a variable of type $\mathrm{P}$, preserving the typing introduced by the verbal projection of 'picked up'.

Now let us look at the copredication sentences (50) and (85), repeated below.

John mastered three heavy books.

John picked up and mastered three books.

By the Head Typing Princple, what has to happen compositionally in (50) is that first the physical typing of the adjective 'heavy' has to be accommodated to the dot-typing of the noun 'books', and then the dot typing of the DP 'three heavy books' has to be accommodated

\footnotetext{
${ }^{23}$ This 'Head Typing Principle', according to which syntactic projection preserves typing, actually follows from more basic assumptions in (Asher, 2011). However, I adopt this simpler presentation (from (Asher and Pustejovsky, 2006) and (Asher, 2008)) for expository purposes and also because deriving the Head Typing Principle seems to be the aim of some of those assumptions.
} 
to the informational typing of the verbal projection. This leaves us with the interpretation shown in (118).

$$
\begin{aligned}
\lambda \pi . \exists v & \left(v=j^{\prime}(\pi) \wedge \exists_{3} x\left(\operatorname { m a s t e r } ^ { \prime } ( v , x , \pi ) \wedge \exists z \left(\operatorname{book}^{\prime}(z, \pi) \wedge \text { o-elab }(x, z, \pi)\right.\right.\right. \\
& \left.\left.\left.\wedge \exists y\left(\operatorname{heavy}^{\prime}(y, \pi) \wedge \text { o-elab }(y, z, \pi)\right)\right)\right)\right) \\
\pi: & x: \mathrm{I}, y: \mathrm{P}, z: \mathrm{P} \bullet \mathrm{I}
\end{aligned}
$$

What (118) says is that there are three objects of type I (information), each of which was mastered by John, and each of which is an aspect of a book that (also) has an aspect of type P (physical) that is heavy. By looking at (108) and (109), we can see that the prediction here is that (50) should be true in a situation in which John mastered the informational contents of three books printed in a single physical volume, such as the situation shown in Figure 3. There, on either conceptualisation, we have three objects of type I (Notes from Underground, The Gambler, and The Double), each of which is an aspect of some book that itself has a(nother) aspect of type P (vol 1, vol 2 or vol 3). But clearly (50) would not be true in such a situation, as there are not three heavy books.

One might think that there is a way to remedy this situation by reformulation of the conditions determining what type is accommodated to what. But analysis of (85) shows that this is not the case.

In (85) the type conflict occurs within the verbal coordination 'picked up and mastered' and is not one involving a clash between $\alpha \bullet \beta$ and $\alpha$, but rather between $\alpha$ and $\beta$ (in this case, $\mathrm{P}$ and I). Concretely, the coordination of the two transitive verbs initially delivers the interpretation shown in (119), where $\Phi$ and $\Psi$ are variables ranging over DP denotations.

$$
\begin{gathered}
\lambda \Phi \cdot \lambda \Psi \cdot \lambda \pi_{1} \cdot \Psi\left(\pi_{1} * \arg _{1}^{\text {pick-up }^{\prime}}: \mathrm{H} * \arg _{1}^{\text {master }^{\prime}}: \mathrm{H}\right) \\
\left(\lambda x \cdot \lambda \pi_{2} . \Phi\left(\pi_{2} * \arg _{2}^{\text {pick-up }^{\prime}}: \mathrm{P} * \arg _{2} \text { master }^{\prime}: \mathrm{I}\right)\right. \\
\left.\left(\lambda y \cdot \lambda \pi_{3}\left(\operatorname{pick}^{\prime} \operatorname{up}^{\prime}\left(x, y, \pi_{3}\right) \wedge \operatorname{master}^{\prime}\left(x, y, \pi_{3}\right)\right)\right)\right)
\end{gathered}
$$

In (119), the sequence of type presuppositions shown in $\pi_{2}$ cannot be jointly satisfied. To deal with this situation, Asher $(2011,176)$ proposes an additional rule for coordination structures that effectively splits up $\pi_{2}$ and allows those type requirements to remain unresolved until the formation of the whole VP. So (119) is transformed into (120).

$$
\begin{aligned}
& \lambda \Phi . \lambda \Psi \cdot \lambda \pi_{1} \cdot \Psi\left(\pi_{1} * \arg _{1}^{\text {pick-up' }^{\prime}}: \mathrm{H} * \arg _{1}^{\text {master' }^{\prime}}: \mathrm{H}\right) \\
& \left(\lambda x \cdot \lambda \pi_{2} . \Phi\left(\pi_{2}\right)\left(\lambda y \cdot \lambda \pi _ { 3 } \left(\text { pick-up }^{\prime}\left(x, y, \pi_{3} * \arg _{2}^{\text {pick-up' }}: \mathrm{P}\right)\right.\right.\right. \\
& \left.\left.\left.\wedge \operatorname{master}^{\prime}\left(x, y, \pi_{3} * \arg _{2}^{\text {master' }^{\prime}}: \mathrm{I}\right)\right)\right)\right)
\end{aligned}
$$

When (120) is combined with the interpretation of 'three books', the type presuppositions $\arg _{2}^{\text {pick-up' }}:$ P and $\arg _{2}^{\text {master' }}$ : I can each individually be accommodated by shifting to $\mathrm{P} \bullet \mathrm{I}$. The effect is that that the Head Typing Principle is overridden, as now the whole sentence inherits the typing of the object DP and not that of the verbal projection.

We therefore end up with the interpretation shown in (121) (adapted from Asher, 2011, 178).

$$
\begin{aligned}
\lambda \pi \cdot \exists v & \left(v=\operatorname{John}^{\prime}(\pi) \wedge \exists_{3} x\left(\operatorname{book}^{\prime}(x, \pi) \wedge \exists z\left(\operatorname{pick}_{-u_{p}}(v, z, \pi) \wedge \text { o-elab }(z, x, \pi)\right)\right.\right. \\
& \left.\left.\wedge \exists y\left(\operatorname{master}^{\prime}(v, y, \pi) \wedge \text { o-elab }(y, x, \pi)\right)\right)\right) \\
\pi: & x: \text { P } \bullet \text { I, } y: \text { I, } z: \mathrm{P}
\end{aligned}
$$


In this case, the variable bound by the $\exists_{3}$ quantifier is the dot-typed one itself. Importantly, then, (121) is ambiguous: on one reading, it requires the existence of three booksindividuated-physically, while on the other reading it requires the existence of three booksindividuated-informationally. On neither reading does it require the existence of both.

This is problematic. Consider a situation in which John picks up three copies of the same (informational) book, and masters the contents. Suppose that he picked up all the physical volumes and masters all the informational objects shown in Figure 4. (85) is not true in this situation. But now look at (111). Given a physical criterion of individuation that situation would be one in which (121) is true: there are three objects in the extension of book', each of which has an aspect of physical type that John picked up and each of which has an aspect of informational type that John mastered.

Likewise, (85) is not true in a situation in which John (only) picked up a trilogy and mastered the contents. However, if John picked up all the physical volumes and mastered all the informational objects shown in Figure 3 then, as indicated in (109), given an informational criterion of individuation that situation would then be one in which (121) is true: there are three objects in the extension of book', each of which has an aspect of physical type that John picked up and each of which has an aspect of informational type that John mastered.

So (121) does not accurately represent the truth conditions of (85), nor does (118) accurately represent the truth conditions of (50). Some other approach is needed to derive the truth conditions of numerical quantified copredication sentences.

Another way of putting this is to note that the approach to copredication described in Section 3 predicts the entailments shown in (122)-(123), but TCL does not.

(122) John picked up and mastered three books. $\Rightarrow$ John picked up three books.

(123) John picked up and mastered three books. $\Rightarrow$ John mastered three books.

The cost of denying that (122) and (123) really are entailments is that of denying that (124) and (125) are contradictions.

(124) John picked up and mastered three books, but he didn't pick up three books.

(125) John picked up and mastered three books, but he didn't master three books.

One might think that the appropriate response here is to appeal to some sort of implicit modalisation such that, for (121) to be true, it has to be true on both (or all) possible criteria of individuation. However, on Asher's own terms this is problematic, because it removes some amibiguity in an unwelcome way. For example, consider again take (105). The metalanguage interpretation of this sentence in TCL is shown in (126) (adapted from (Asher, 2011, 174)). ${ }^{24}$

$$
\begin{aligned}
\lambda \pi . & \forall v\left(\exists u \exists x \exists z \left(\operatorname{library}^{\prime}(x, \pi) \wedge \operatorname{in}^{\prime}(u, z, \pi) \wedge \text { o-elab }(z, x, \pi)\right.\right. \\
& \left.\left.\wedge \operatorname{book}^{\prime}(v, \pi) \wedge \text { o-elab }(u, v, \pi)\right) \rightarrow \operatorname{read}^{\prime}\left(s^{\prime}, v, \pi\right)\right) \\
\pi: \quad & s^{\prime}: \mathrm{A}, v: \mathrm{P} \bullet \mathrm{I}, x: \mathrm{P} \bullet \mathrm{L}, u: \mathrm{P}, z: \mathrm{L}
\end{aligned}
$$

As things stand, (126) tracks the ambiguity of (105): on the informational criterion of individuation, (126) is true if John read every informational book of which there is a physical

\footnotetext{
${ }^{24} \mathrm{~L}$ is the type of locations in Asher's system.
} 
volume 1

volume 2

Crime and Punishment

volume $3 \quad \begin{gathered}\text { Notes from Underground } \\ \text { The Gambler } \\ \text { The Double }\end{gathered}$

Figure 5: Two copies of one book, and a trilogy

copy in the library; and on the physical criterion of individuation (126) can only be true if she read every physical book in the library, which normally would require reading some informational books several times. However, if we were to require (126) to be true on both criteria of individuation for the variable $v$, then (126) could only be true if John read every physical copy of every book in the library, which is actually the less favourable of the two readings.

Additionally, even if we go down the route of requiring truth relative to all criteria of individuation, the truth conditions predicted for this amendment to the TCL account will still sometimes differ from those predicted by the account given in Section 3. To see this, we have to consider a slightly more complex situation.

Figure 5 shows a situation that is a partial combination of those shown in Figures 3 and 4: we have two copies of Crime and Punishment, and also Notes from Underground, The Gambler and The Double in a single volume.

Now suppose that John picked up volumes 1-3, and that he mastered Crime and Punishment, Notes from Underground, The Gambler and The Double. As Figure 6 shows, on both criteria of individuation there are at least three books that meet the following criteria: they have an aspect of type $\mathrm{P}$ that John picked up, and they have an aspect of type I that John mastered. Therefore, according to the proposed revision to the TCL system, (85) would be true in this situation. ${ }^{25}$

In contrast, according to the account described in Section 3, (85) is not true in that situation, because every three-or-more-membered plurality that can be formed from the set shown in (127) is physically or informationally compressible, and so the truth conditions for (85) as predicted in the account from Section 3, repeated below as (128), are not satisfied.

$$
\begin{aligned}
& \left\{v_{1}+C \mathscr{G} P, v_{2}+C \mathscr{S} P, v_{3}+N f U, v_{3}+T G, v_{3}+T D\right\} \\
& \exists x\left(|x| \geq 3 \wedge{ }^{*} \operatorname{book}^{\prime}(x) \wedge{ }^{*} \operatorname{pick}^{\prime} \operatorname{up}^{\prime}\left(j^{\prime}, x\right) \wedge{ }^{*} \operatorname{master}^{\prime}\left(j^{\prime}, x\right) \wedge \neg(\text { PHYS } \sqcup \operatorname{INFO}) \operatorname{comp}(x)\right)
\end{aligned}
$$

It is my judgement that the revised mereological approach to copredication makes better predictions here than the proposed revisions to the TCL system: (85) is false in the situation shown in Figure 5.

In summary: the truth conditions that the TCL account predicts for numerically quantified copredication sentences are too permissive - it predicts some sentences to be true in

\footnotetext{
${ }^{25}$ Again, taking 'three' to mean 'at least three'.
} 

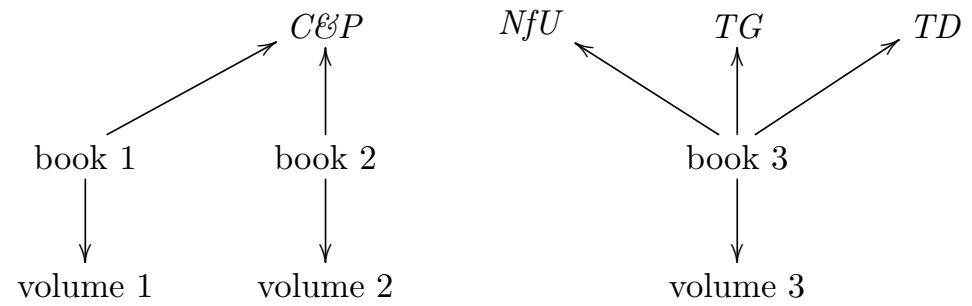

Physical individuation:

3 books
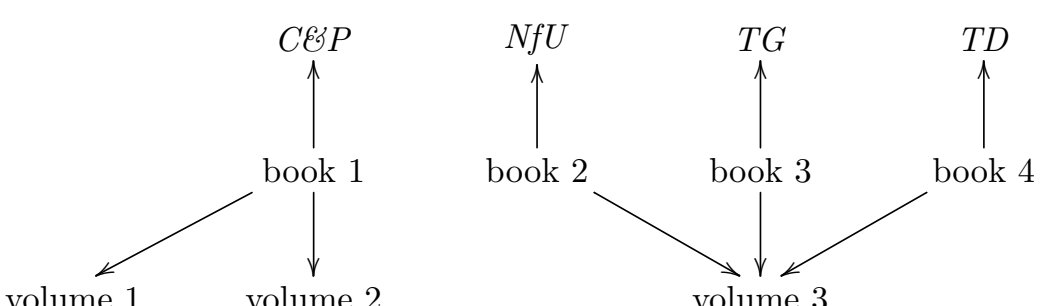

Informational individuation:

volume $1 \quad$ volume 2

Figure 6: Figure 5 according to physical and informational criteria of individuation

situations where they are not. There are ways in which the system could be improved so as to make the truth conditions more restrictive, but these will not work in every case.

\subsection{Type Theory with Records}

Type Theory with Records (TTR) is an application of intuitionistic type theory to formal semantic composition motivated by the desire to unify it with other approaches in linguistics and artificial intelligence (Cooper, 2005).

In this formalism, records are sets of ordered pairs (called fields) of labels and values, and record types are records where all the values are types. Record types are sets of type judgements, and they correspond to propositions in more standard theories. The counterpart in TTR of a proposition being true is a record type being witnessed. A record type $r_{t}$ is witnessed if and only if there is a record $r$ in which all of the type judgements in $r_{t}$ are satisfied. In this case, $r$ is a record of the type $r_{t}$. In a record the values (paired with labels) can be objects, proofs or types.

To give a concrete example: if $a$ is an individual (an object of type $I n d$ ) and $p_{1}$ is a proof that $a$ is food, then the record type (129) is witnessed by the record (130). ${ }^{26}$

${ }^{26}$ The field ' $\mathrm{c}_{1}$ : food(x)' in (129) is actually shorthand for the field shown in (i).

$$
\mathrm{c}_{1}:\langle\lambda v: \operatorname{Ind}(\operatorname{food}(v)),\langle\mathrm{x}\rangle\rangle
$$

That is to say, the arguments to a predicate are not actually labels, but objects. The type of ' $\mathrm{c}_{1}$ ' in (i) is a pair, the first member of which is a function (from individuals to proofs) and the second member of which gives us the label indicating where the object that is the argument to that function is to be found (Cooper, $2012, \S 2.5)$. In the case of a more-than-one-place predicate, the second member of the pair will of course be a correctly-ordered list of fields of appropriate length. 
(129)

$$
\begin{aligned}
& \left\{\langle\mathrm{x}, \text { Ind }\rangle,\left\langle\mathrm{c}_{1}, \operatorname{food}(\mathrm{x})\right\rangle\right\} \text {, usually represented as }\left[\begin{array}{lll}
\mathrm{x} & : & \text { Ind } \\
\mathrm{c}_{1} & : & \text { food }(\mathrm{x})
\end{array}\right]
\end{aligned}
$$

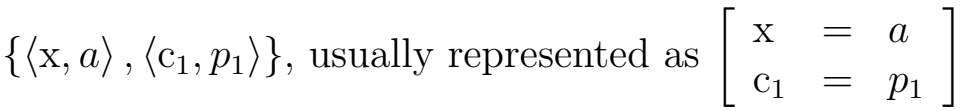

Cooper $(2011,76)$ suggests that the dot types of Generative Lexicon theory (Pustejovsky, 1995) and Asher's extension of it 'can be usefully construed as record types'. For example, the lexical entry for 'lunch' that he suggests is as follows:

$$
\llbracket \text { lunch } \rrbracket=\lambda r:[\mathrm{x}: \text { Ind }]\left(\left[\begin{array}{ll}
\text { event } & : \text { Event } \\
\text { food } & : \text { Food } \\
c_{\text {lunch }}: & \text { lunch_ev_fd }(r . \mathrm{x}, \text { event }, \text { food })
\end{array}\right]\right)
$$

What (131) represents is a function from records $r$ in which ' $\mathrm{x}$ ' labels an individual to record types containing proofs ( $c_{\text {lunch }}$ ) that that individual is a lunch and that it has an aspect (labelled 'event') of type Event and an aspect (labelled 'food') of type Food. We are to imagine the predicate 'lunch_ev_fd' holding true of ordered triples of objects $\langle x, y, z\rangle$ such that $x$ is a lunch individual with event aspect $y$ and food aspect $z$. ' $r$.x' indicates the label ' $\mathrm{x}$ ' in the record ' $r$ ' that is the argument to the function. ${ }^{27}$ The idea is that you could apply (131) to the record shown in (132) (where $a$ is an individual) and obtain the record type shown in (133).

$$
\begin{aligned}
& {[\mathrm{x}=a]} \\
& {\left[\begin{array}{l}
\text { event }: \text { Event } \\
\text { food }: \text { Food } \\
\text { clunch }: \text { lunch_ev_fd }(a, \text { event }, \text { food })
\end{array}\right]}
\end{aligned}
$$

More generally, (131) is a function from records introducing an individual to record types; that is, it is of the type shown in (134) (Cooper, 2011, 68).

$$
[\mathrm{x}: \text { Ind }] \rightarrow \text { RecType }
$$

The type shown in (134) can be referred to as Ppty, for 'property'. Cooper sees it as an advantage of his strategy for copredication that this type is not a special kind of unusual type that only nouns supporting copredication have - which is the status that dot types have in Asher's (2011) theory. Rather, it is the normal type of nouns in TTR: essentially, (131) can be seen as representing the property of being a lunch, for example. It is, in fact, a function from something like individuals to something like propositions.

The exact form of the record types involved in this formalisation has changed as a result of the attempt to incorporate copredication. For instance, in previous versions (Cooper, 2007, for example), 'lunch' was represented as shown in (135).

$$
\llbracket \text { lunch } \rrbracket=\lambda r:\left[\begin{array}{lll}
\mathrm{x} & : & \operatorname{Ind} \\
\mathrm{c}_{1} & : & \operatorname{food}(\mathrm{x}) \\
\mathrm{c}_{2} & : & \operatorname{event}(\mathrm{x})
\end{array}\right]\left(\left[\mathrm{c}_{3}: \operatorname{lunch}(r \cdot \mathrm{x})\right]\right)
$$

\footnotetext{
${ }^{27}$ This is known as a path to the label $\mathrm{x}$ in $\mathrm{r}$.
} 
The move from (135) to (131) is motivated in part by the fact that (135), and not (131), makes the (apparently) dubious requirement that something (labelled ' $\mathrm{x}$ ') can be both food and an event. As indicated in Section 2, Cooper (2007) explained this requirement by saying that the food and the event would both be parts of a lunch, but this mereological account was not further developed and has been abandoned.

Adapting the lexical entry for 'lunch' shown in (131), the lexical entry for 'book' is as shown in (136).

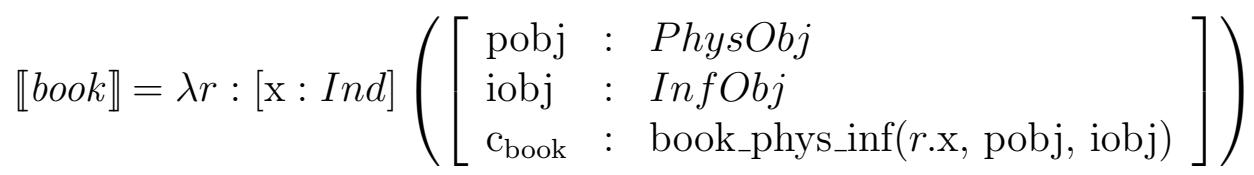

What (136) shows is a function from records $r$ containing the declaration that the object labelled ' $\mathrm{x}$ ' is of type Ind (individual) to records, dependent on $r$, declaring that the object labelled ' $\mathrm{x}$ ' is a book that has physical aspect labelled 'pobj' and an informational aspect labelled 'iobj'.

In order to express quantification, determiner meanings are treated by giving formulae that will translate the type-theoretic expressions of TTR into set-theoretic expressions, such that relations between them can be defined as in generalised quantifier theory (Barwise and Cooper, 1981, for example). This is done in two stages (Cooper, 2011, 69-70). First, for any type $T$, we can talk about the the extension of $T$, written $\left[{ }^{\vee} T\right]$, which is the set of things that are of type $T$. A definition is given in (137).

$$
\left[{ }^{\vee} T\right] \stackrel{\text { def }}{=}\{a \mid a: T\}
$$

If $T$ is of type Ppty, then (this is the second stage) we can talk about the set of things that have the property expressed by $T$, the property extension of $T$ or $[\downarrow T]$. The definition of this is shown in (138).

$$
[\downarrow T] \stackrel{\text { def }}{=}\left\{a \mid \exists r\left(r:[\mathrm{x}: I n d] \wedge r . \mathrm{x}=a \wedge\left[{ }^{\vee} T(r)\right] \neq \emptyset\right)\right\}
$$

This is the set of things $a$ such that $a$ is of type Ind and $[x=a]$ is a record that bears the property expressed by $T$. For any determiner meaning $q *$ given as a relation between sets, we can define an equivalent determiner meaning $q$ in TTR in terms of a relation between functional record types, as in (139) (where $A$ and $B$ are of type Ppty).

$$
q(A, B) \Leftrightarrow q^{*}([\downarrow A],[\downarrow B])
$$

This means that the truth conditions predicted for (4) (repeated below) are as shown in (140).

(4) Three books are heavy.

(140) $\mid[\downarrow \llbracket$ book $\rrbracket] \cap[\downarrow \llbracket$ heavy $\rrbracket \mid \geq 3$

Using the definition of property extension shown in (138) and the lexical entry for 'book' 
shown in (136), $[\downarrow \llbracket b o o k \rrbracket$ is as shown in (141).

$$
\begin{aligned}
\{a \mid \exists r([\mathrm{x}: \text { Ind }] \wedge r . \mathrm{x}=a & \\
& \left.\left.\wedge\left\{b \mid b:\left[\begin{array}{ll}
\text { pobj } & : \text { PhysObj } \\
\text { iobj } & : \text { InfObj } \\
c_{\text {book }}: & \text { book_phs_inf }(r . x, p o b j, \text { iobj })
\end{array}\right]\right\} \neq \emptyset\right)\right\}
\end{aligned}
$$

This is the set of things $a$ such that $a$ is of type Ind and there is at least one record proving that $a$ stands in the book_phs_inf relation to something of type PhysObj and something of type InfObj. So it is the set of books.

Likewise, assuming the lexical entry for 'heavy' shown in (142) (based on the entry for 'delicious' (Cooper, 2011, 72)), it follows that $[\downarrow \llbracket$ heavy $\rrbracket$ is as shown in (143).

$$
\begin{gathered}
\llbracket h e a v y \rrbracket=\lambda r_{1}:\left[\begin{array}{lll}
\mathrm{x} & : & \text { Ind } \\
\text { pobj } & : & \text { PhysObj }
\end{array}\right]\left(\left[\text { cheavy }_{\text {he_heavy_phs }}\left(r_{1} \cdot \mathrm{x}, r_{1} \cdot \mathrm{pobj}\right)\right]\right) \\
\left\{a \mid \exists r\left(r:\left[\begin{array}{ll}
\mathrm{x} \quad: & \text { Ind } \\
\text { pobj }: & \text { PhysObj }
\end{array}\right] \wedge r \cdot \mathrm{x}=a\right.\right. \\
\left.\left.\wedge\left\{b \mid b:\left[c_{\text {heavy }}: \text { be_heavy_phs }(r \cdot \mathrm{x}, r \cdot \operatorname{pobj})\right]\right\} \neq \emptyset\right)\right\}
\end{gathered}
$$

But in what sense is (141) the set of books? As we have seen, books can be individuated and counted in different ways depending on the predicational context. It cannot be that the truth conditions of (4) are as shown in (140) and that the truth conditions of (5) (repeated below) are as shown in (144), because the relevant set of books in (4) and (5) could have different cardinalities, as we have seen.

(5) Three books are informative.

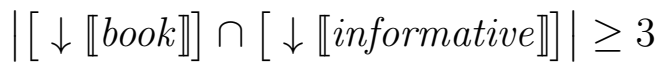

In response to these issues of counting and individuation, Cooper $(2011,76)$ suggests that 'given that we now have aspects in separate fields of our frames we could relativize our notion of property extension to labels in the frame'. ${ }^{28}$ A definition of the property extension of property type $T$ relative to label $1,\left[\downarrow_{l} T\right]$, is given in (145).

$$
\left[\downarrow_{l} T\right] \stackrel{\text { def }}{=}\left\{a \mid \exists r\left(r:[\mathrm{x}: \text { Ind }] \wedge r .1=a \wedge\left[{ }^{\vee} T(r)\right]\right) \neq \emptyset\right\}
$$

This now allows us to count books relative to different criteria of indivduation. For instance, to get the set of books individuated physically we can instantiate $l$ as 'pobj', as in (146).

$$
\left[\downarrow_{\text {pobj }} T\right] \stackrel{\text { def }}{=}\left\{a \mid \exists r\left(r:[\mathrm{x}: \text { Ind }] \wedge r \cdot \operatorname{pobj}=a \wedge\left[{ }^{\vee} T(r)\right]\right) \neq \emptyset\right\}
$$

\footnotetext{
${ }^{28}$ In fact, Cooper $(2011,75-76)$ gives suggestions of various additional ways in which we might individuate and count books over and above the physical and informational ways that we have been considering.
} 
Then, if we take $\left[\downarrow_{\text {pobj }}(136)\right]$, we have the set shown in (147), which is the set of books individuated physically.

$$
\begin{aligned}
& \{\mid \exists r([\mathrm{x}: \text { Ind }] \wedge r \cdot \mathrm{pobj}=a
\end{aligned}
$$

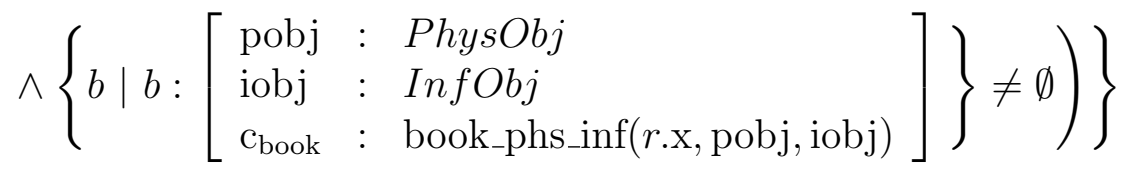

This is the set of things $a$ such that $a$ is of type PhysObj and there is at least one record proving that something of type Ind stands in the book_phs_inf relation to $a$ and something of type InfObj. So it is the set of physical aspects of books. We therefore have a way of counting relative to a physical criterion of individuation.

Alternatively, to get the set of books individuated informationally we can instantiate $l$ as 'iobj', as in (148).

$$
\left[\downarrow_{\text {iobj }} T\right] \stackrel{\text { def }}{=}\left\{a \mid \exists r\left(r:[\mathrm{x}: \text { Ind }] \wedge r . \text { iobj }=a \wedge\left[^{\vee} T(r)\right]\right) \neq \emptyset\right\}
$$

Then, if we take $\left[\downarrow_{\text {iobj }}(136)\right]$, we have the set shown in (149), which is the set of books individuated informationally.

$$
\begin{aligned}
& \{a \mid \exists r([\mathrm{x}: \text { Ind }] \wedge r . \mathrm{iobj}=a
\end{aligned}
$$

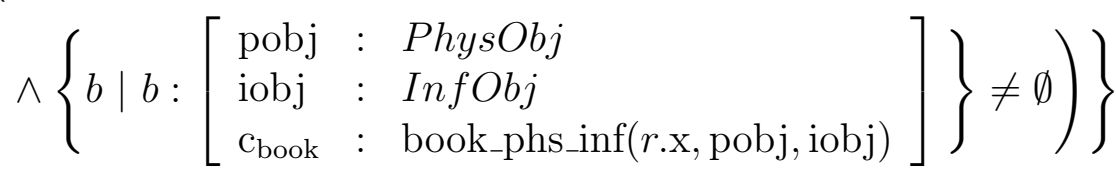

This approach can get the correct truth conditions for (48) and (49)-although even in these cases more needs to be said about the necessary constraints on what relative property extension can be taken for each sentence (e.g. we don't want to take the property extension

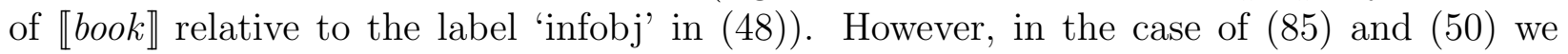
need something else, because neither taking the property extension relative to 'physobj' nor taking it relative to 'infobj' would give us truth conditions restricted enough for those sentences. In this system, there is a mechanism for enforcing physical distinctness, and a mechanism for enforcing informational distinctness, but not for enforcing both at the same time, as is needed in the case of copredication. For that we need to be able to talk about whole pluralities, and make compressibility statements about those pluralities, as described in Section 3.

\subsection{Modern Type Theories}

Luo (2010, 2011, 2012b) and Chatzikyriakidis and Luo (2012, 2013, 2015) also adopt a compositional framework according to which predicates impose sortal requirements on their arguments, requirements that are encoded in the type system. That system, which they call 
a 'modern type theory' (MTT) ${ }^{29}$ is based on a many-sorted logic and involves a subtyping relationship $<_{c}$, where $A<_{c} B$ indicates that there is a unique implicit coercion from type $A$ to type $B$. This means that an object of type $A$ can be used in any context requiring an object of type $B .{ }^{30}$ Like Asher's TCL (see Section 4.1), the type hierarchy is very fine-grained and it includes dot types.

Unlike the dot types in Asher's TCL, the dot types in this system generally are in a subtyping relationship with their constituent types. For instance, we have the relationships shown in (150).

\section{PHYS $\bullet \mathrm{INFO}<_{c}$ PHYS \\ $\mathrm{PHYS} \bullet \mathrm{INFO}<_{c} \mathrm{INFO}$}

One problem that immediately arises in taking this kind of approach to dot types and subtyping is that the the subtyping relationships shown in (150) do not generalize to higher types in the way we would want, as indicated in $151 .^{31}$

$$
\begin{aligned}
& (\mathrm{PHYS} \bullet \mathrm{INFO}) \rightarrow \text { Prop } \nless_{c} \text { PhYs } \rightarrow \text { Prop } \\
& (\mathrm{PHYS} \bullet \mathrm{INFO}) \rightarrow \text { Prop } \nless_{c} \quad \mathrm{INFO} \rightarrow \text { Prop }
\end{aligned}
$$

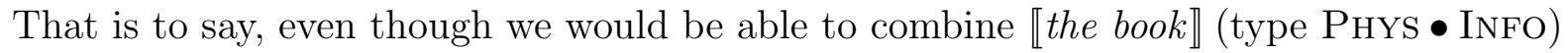

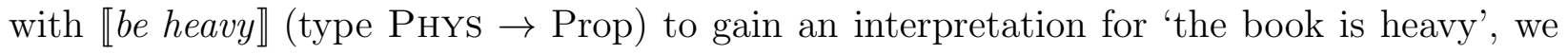

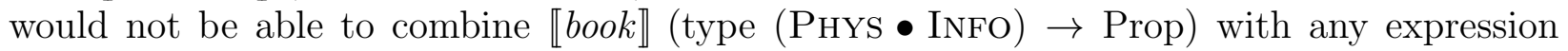
requiring an argument of type PHYs $\rightarrow$ Prop. Instead, by contravariance, we have the subtyping relationships shown in (152).

$$
\begin{aligned}
& \text { PHYS } \rightarrow \text { Prop }<_{c} \quad(\text { PhYs } \bullet \text { INFO }) \rightarrow \text { Prop } \\
& \mathrm{INFO} \rightarrow \text { Prop }<_{c}(\text { PHYS } \bullet \text { INFO }) \rightarrow \text { Prop }
\end{aligned}
$$

The MTT solution to this is to allow abstraction over types and to say that common nouns denote types (Luo, 2012a). So for example the word 'book' denotes the type Book, which is part of the subtype hierarchies shown in (153).

$$
\begin{array}{lll}
\text { BOOK }<_{c} & \text { PHYS } \bullet \text { INFO }<_{c} \text { PHYS } \\
\text { BOOK }<_{c} \text { PHYS } \bullet \text { INFO }<_{c} \text { INFO }
\end{array}
$$

And so by contravariance we also have the subtyping relationships shown in (154).

$$
\begin{aligned}
& \text { Phys } \rightarrow \text { Prop }<_{c}(\text { Phys } \bullet \mathrm{INFO}) \rightarrow \text { Prop }<_{c} \text { BooK } \rightarrow \text { Prop } \\
& \text { InFO } \rightarrow \text { Prop }<_{c}(\text { Phys } \bullet \text { InFO }) \rightarrow \text { Prop }<_{c} \text { BooK } \rightarrow \text { Prop }
\end{aligned}
$$

\footnotetext{
${ }^{29}$ Modern, because it is an advance on the simple type theory, based on a single-sorted logic, adopted by Montague (1973) and the work in natural language semantics that he ushered in.

${ }^{30}$ This is called 'coercive subtyping'.

31'Prop' is the type of propositions, which would be type $t$ (or perhaps $s \rightarrow t$ ) in a simply-typed system.
} 
Of course this involves taking a novel look at various other lexical entries as well, which I will now illustrate on the basis of some examples. Let us first consider the non-copredication sentences (48)-(49). (48) is interpreted as shown in (155). ${ }^{32,33}$

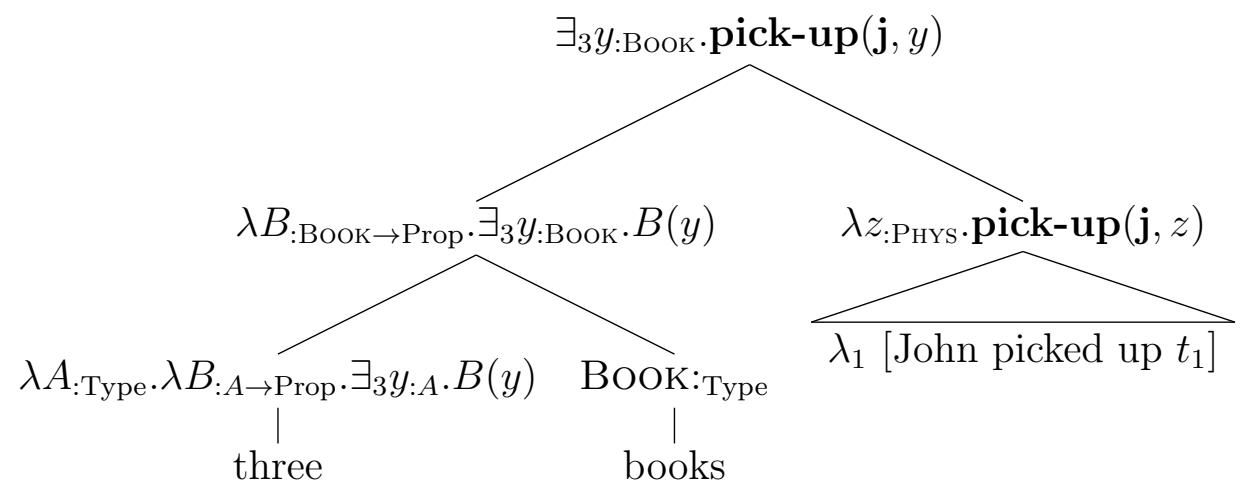

As can be seen from (155), because the determiner takes a type as its first argument, which is

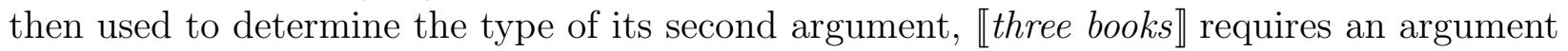
of type BooK $\rightarrow$ Prop. The argument provided in fact is of type PHYS $\rightarrow$ Prop, meaning that composition can proceed because, as can be seen from the subtype hierarchy in (154), PHYs $\rightarrow$ Prop is a subtype of BooK $\rightarrow$ Prop- so $\llbracket \lambda_{1}\left[\right.$ John picked up $\left.t_{1}\right] \rrbracket$ can be coerced to be of type Book $\rightarrow$ Prop.

(49) is interpreted as shown in (156).

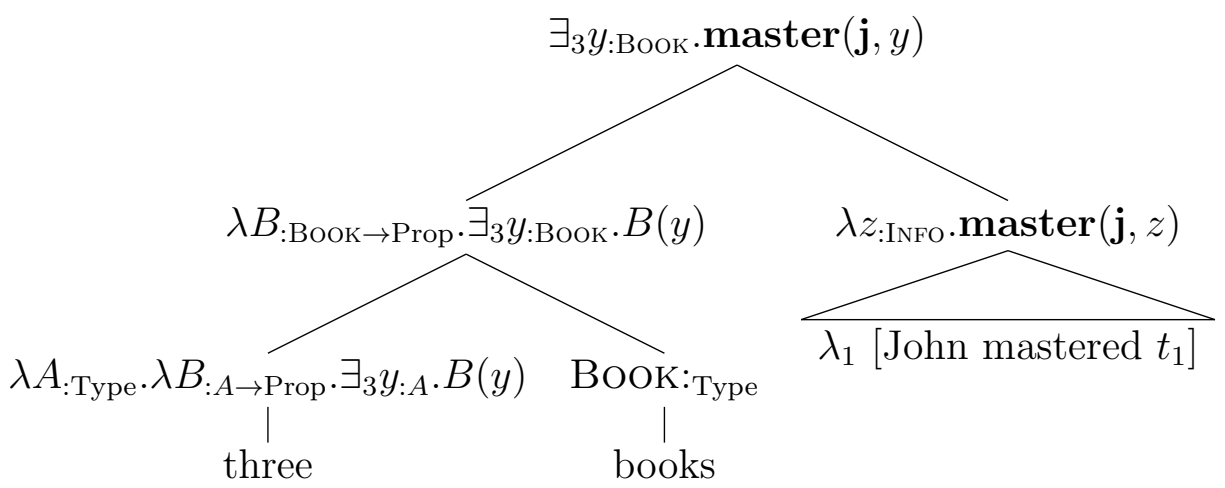

INFO $\rightarrow$ Prop is a subtype of BooK $\rightarrow$ Prop, so $\llbracket \lambda_{1}\left[\right.$ John mastered $\left.t_{1}\right] \rrbracket$ can be coerced to be of type BoOK $\rightarrow$ Prop.

What should be noted is that, in both these cases, composition can proceed ultimately because some other type can be coerced to the type BooK $\rightarrow$ Prop, and so in the end we have quantifiction over objects of type Book. Exactly the same thing is the case for cases of copredication. For example, let us consider (85). According to the theory of coordination

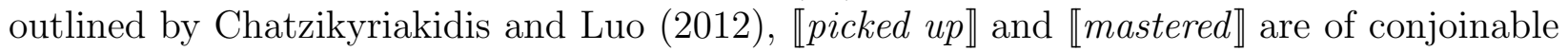

\footnotetext{
${ }^{32}$ N.B. this representation has been chosen for ease of comprehension and is not meant to indicate that Chatzikyriakidis and Luo are committed to quantifier raising, or indeed any particular syntactic claims other than that 'three books' is a constituent.

${ }^{33}$ In the following examples I will use $\exists_{3} x_{: T}$. $\Phi[x]$ as an abbreviation for $\exists x_{1: T} \exists x_{2: T} \exists x_{3: T} . \Phi\left[x_{1}\right] \wedge \Phi\left[x_{2}\right] \wedge$ $\Phi\left[x_{3}\right] \wedge x_{1} \neq x_{2} \wedge x_{1} \neq x_{3} \wedge x_{2} \neq x_{3}$, corresponding to the semantics that Chatzikyriakidis and Luo (2015) give for 'three'.
} 
types, because both can be coerced to a common type: (PHYs $\bullet$ INFO $) \rightarrow($ HumAN $\rightarrow$ Prop). This is shown in (157).

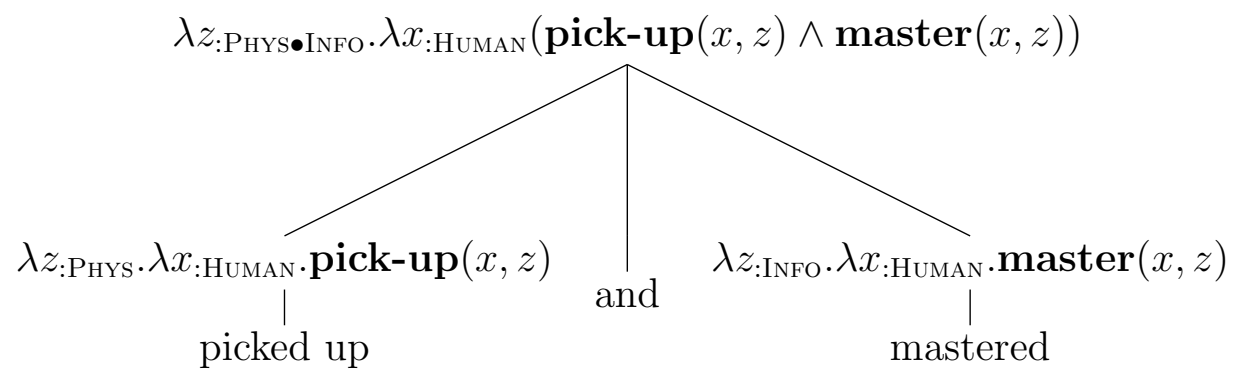

And then, since $($ Phys $\bullet$ INFO) $\rightarrow$ Prop is a subtype of Book $\rightarrow$ Prop (as shown in (154)), interpretation of (85) proceeds as shown in (158).

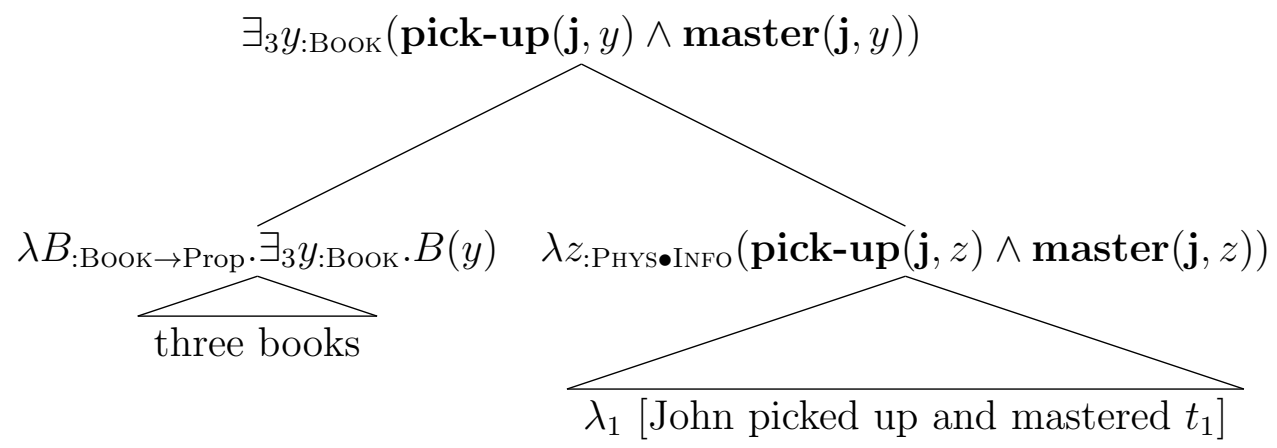

As in both the previous examples, we have quantification over objects of type Book, with no additional specifications being made as to what will count as a book in any case. This is characteristic of the MTT approach: quantification always ends up being over objects of dot type when the noun in the quantified noun phrase is of dot type.

Chatzikyriakidis and Luo (2015) point out that their system (unlike the other theories addressed in this section) correctly predicts the entailments shown in (122)-(123), and also the entailment shown in (159).

(159) John picked up and mastered three books $\Rightarrow$ John picked up three physical objects and John mastered three informational objects.

However, it does this because it predicts double-distinct individuation in all cases, not just those involving copredication. This causes problems in cases where we do not want to predict double-distinctness. One way of seeing this is to note that the system presented by Chatzikyriakidis and Luo (2015) predicts the arguments shown in (100) and (160) to be valid. ${ }^{34}$

\footnotetext{
${ }^{34}$ To check this, implement the Coq code described by Chatzikyriakidis and Luo $(2015,43)$ and formulate the theorems to be proved as follows:

(100): Theorem DT: ((Three Book) (picked_up John) 八 forall x:Book, (mastered John x)) -> (Three Book) (mastered John).

This can be proven with a single application of the AUTO tactic.

(160): Theorem DT: ((Three Book) (picked_up John) 八 forall x:Book, (mastered John $\mathrm{x})$ ) $\rightarrow>$ (Three Info) (mastered John).

Tactics: compute. intro. destruct H. destruct H. exists $x$. apply conj. apply HO.
} 
John mastered three informational objects.

These are not welcome results. There might be a situation in which there are three copies of the same book, and John picks them all up and masters the contents. In that situation it seems that the two premises of (100) and (160) would be true, but their conclusions would be false. The system described in this paper does not predict these arguments to be valid, as can be seen from the discussion in Section 3.3.2.

I conclude that none of the theories reviewed in this section makes all the right distinctions between physical predication, informational predication and copredication needed in order to account for all the individuation data in these cases.

\section{Conclusion}

The phenomenon of copredication indicates that the way in which we as speakers conceptualize the link between words and objects is not uniform. For the most part, (disambiguated) nouns make the same contribution to sentential truth conditions whatever is predicated of them-but that is not the case for nouns supporting copredication, as we can seen from the varying criteria of individuation and counting for 'book'.

However, this is not to say that the contribution is unsystematic. In this paper I have proposed that criteria of individuation for nouns supporting copredication are determined compositionally. This is achieved by associating lexical entries with additional information that is relevant to individuation, and specifically allowing numerical determiners to access that information and exploit it in placing additional requirements on the pluralities over which they existentially quantify. This approach constitutes an advance on other accounts proposed so far, which cannot deliver all the criteria of individuation necessary for copredication and non-copredication sentences.

\section{Acknowledgements}

This paper is based on parts of Chapters 2, 3 and 4 of my thesis (Gotham, 2014), which was funded by the Arts and Humanities Research Council, whose support is gratefully acknowledged. Many thanks too to Nathan Klinedinst, Yasu Sudo, Robin Cooper and Stergios Chatzikryiakidis for extensive discussion and comments, and to two anonymous reviewers for helpful suggestions.

destruct $\mathrm{H}$. destruct $\mathrm{H} 1$. exists $\mathrm{x} 0$. AUTO.

The proof of (160), but not that of (100), requires the auxiliary assumptions discussed in footnote 9 , and defined in Appendix A, of Chatzikyriakidis and Luo (2015). 


\section{References}

Asher, Nicholas (2008), A type driven theory of predication with complex types. Fundamenta Informaticae 84:151-183.

Asher, Nicholas (2011), Lexical Meaning in Context: A Web of Words. Cambridge University Press. Cambridge.

Asher, Nicholas \& James Pustejovsky (2006), A type composition logic for generative lexicon. Journal of Cognitive Science 6:1-38.

Barwise, Jon \& Robin Cooper (1981), Generalized quantifiers and natural language. Linguistics and Philosophy 4:159-219.

Beck, Sigrid \& Uli Sauerland (2000), Cumulation is needed: A reply to Winter (2000). Natural Language Semantics 4:349-371.

Chatzikyriakidis, Stergios \& Zhaohui Luo (2012), An account of natural language coordination in type theory with coercive subtyping. In Denys Duchier \& Yannick Parmentier (eds.), 7th International Workshop on Constraint Solving and Language Processing. Number 8114 in Lecture Notes in Computer Science. Springer. Berlin/Heidelberg. 1-17.

Chatzikyriakidis, Stergios \& Zhaohui Luo (2013), Adjectives in a modern type-theoretical setting. In Glyn Morrill \& Mark-Jan Nederhof (eds.), Formal Grammar. Number 8036 in Lecture Notes in Computer Science. Springer. 159-174.

Chatzikyriakidis, Stergios \& Zhaohui Luo (2015), Individuation criteria, dot-types and copredication: A view from modern type theories. In Proceedings of the 14 th Meeting on the Mathematics of Language (MoL 2015). Association for Computational Linguistics. Chicago, USA. 39-50. URL http://www. aclweb.org/anthology/W15-2304.

Chomsky, Noam (2000), New Horizons in the Study of Language and Mind. Cambridge University Press. Cambridge.

Cooper, Robin (2005), Records and record types in semantic theory. Journal of Logic and Computation 15:99-112.

Cooper, Robin (2007), Copredication, dynamic generalized quantification and lexical innovation by coercion. In P. Bouillon, L. Danlos, \& K. Kanzaki (eds.), Fourth International Workshop on Generative Approaches to the Lexicon. Paris, France. URL http://www.ling.gu.se/ cooper/records/copredinnov.pdf.

Cooper, Robin (2011), Copredication, quantification and frames. In Sylvain Pogodalla \& Jean-Philippe Prost (eds.), Logical Aspects of Computational Linguistics. Number 6736 in Lecture Notes in Computer Science. Springer. Berlin/Heidelberg. 64-79.

Cooper, Robin (2012), Type theory and semantics in flux. In Ruth Kempson, Tim Fernando, \& Nicholas Asher (eds.), Philosophy of Linguistics. Volume 14 of The Handbook of the Philosophy of Science. Elsevier. Amsterdam. 271-324. 
Gotham, Matthew (2012), Numeric quantification in copredication. UCL Working Papers in Linguistics 24:1-20.

Gotham, Matthew (2014), Copredication, Quantification and Individuation. Unpublished Ph.D. thesis. Dept. of Linguistics. UCL. London.

Heim, Irene \& Angelika Kratzer (1998), Semantics in Generative Grammar. Number 13 in Blackwell Textbooks in Linguistics. Wiley-Blackwell. Oxford.

Keenan, Edward L. \& Leonard M. Faltz (1985), Boolean Semantics for Natural Language. Number 23 in Studies in Linguistics and Philosophy. D. Reidel. Dordrecht.

Link, Godehard (1983), The logical analysis of plurals and mass terms: A lattice-theoretical approach. In Rainer Bäuerle, Christoph Schwarze, \& Arnim von Stechow (eds.), Meaning, Use and the Interpretation of Language. Walter de Gruyter. Berlin. 302-323.

Luo, Zhaohui (2010), Type-theoretical semantics with coercive subtyping. In Nan Li \& David Lutz (eds.), Proceedings of SALT 20. CLC Publications. Ithaca, NY. 38-56.

Luo, Zhaohui (2011), Contextual analysis of word meanings in type-theoretical semantics. In Sylvain Pogodalla \& Jean-Philippe Prost (eds.), Logical Aspects of Computational Linguistics. Number 6736 in Lecture Notes in Computer Science. Springer. Berlin/Heidelberg. 159-174.

Luo, Zhaohui (2012a), Common nouns as types. In D. Bechet \& A. Dikovsky (eds.), Logical Aspects of Computational Linguistics. Number 7351 in Lecture Notes in Computer Science. Springer. Berlin/Heidelberg. 173-185.

Luo, Zhaohui (2012b), Formal semantics in modern type theories with coercive subtyping. Linguistics and Philosophy 35:491-513.

Montague, Richard (1973), The proper treatment of quantification in ordinary English. In Patrick Suppes, Julius Moravcsik, \& Jaakko Hintikka (eds.), Approaches to Natural Language. D. Reidel. Dordrecht. 221-242.

Partee, Barbara Hall \& Mats Rooth (1983), Generalized conjunction and type ambiguity. In Rainer Bäuerle, Christoph Schwarze, \& Arnim von Stechow (eds.), Meaning, Use and the Interpretation of Language. Walter de Gruyter. Berlin. 361-393.

Pustejovsky, James (1995), The Generative Lexicon. MIT Press. Cambridge, MA.

Varzi, Achille (2012), Mereology. In Edward N. Zalta (ed.), The Stanford Encyclopedia of Philosophy. Winter 2012 edition. URL http://plato.stanford.edu/archives/win2012/ entries/mereology/.

Winter, Yoad \& Remko Scha (2015), Plurals. In Shalom Lappin \& Chris Fox (eds.), The Handbook of Contemporary Semantic Theory. 2nd edition. Wiley-Blackwell. Oxford. 77113. 